\section{The value proposition of food delivery apps from the perspective of theory of consumption value}

Proposition of food delivery apps

Department of Psychosocial Science, University of Bergen, Bergen, Norway and Optentia Research Focus Area, North-West University, Potchefstroom, South Africa

Amandeep Dhir

Department of Management, School of Business and Law, University of Agder, Norway; Norwegian School of Hotel Management, University of Stavanger, Stavanger, Norway and North-West University, Potchefstroom, South Africa

Shalini Talwar

KJ Somaiya Institute of Management, Somaiya Vidyavihar University, Mumbai, India, and

Karminder Ghuman LM Thapar School of Management, Dera-Bassi, India
Received 26 May 2020 Revised 26 August 2020 26 September 2020 Accepted 28 September 2020

Accested 28 stember 2020 
IJCHM 33,4

it adds to the relatively scant literature on FDAs on the whole which is essential, as FDAs represent the business model of new economy, i.e. online-to-offline $(\mathrm{O} 2 \mathrm{O})$. Finally, this study formulates a conceptual framework that may serve as the basis of future research.

Keywords Consumption value, Food-delivery applications, Food safety concern, Health consciousness, Online-to-offline, Visibility

Paper type Research paper

\section{Introduction}

Food delivery applications (FDAs), mobile apps used to order food from food-aggregator platforms, are a subset of online food delivery (OFD) platforms, which include both restaurantto-consumer delivery and food-ordering platforms (aggregator-to-consumer delivery). Jointly, such platforms represent online-to-offline $(\mathrm{O} 2 \mathrm{O})$ services. One can estimate the growing popularity of FDAs from the fact that FDAs are used daily for 15 million food deliveries in China and 1 million food deliveries in India (Jindal, 2018). Notably, Statista (2019) projects the revenue from this platform to the consumer segment to grow globally at $9.8 \%$ from 2019 to 2024 .

While online applications have revolutionized how people shop, even for food, it is necessary to understand how consumers perceive these services. Though scholars have shown increasing interest in studying various aspects of these applications, our extensive literature review reveals that accumulated knowledge on consumer behavior related to OFDs in general and FDAs in particular needs further enrichment. More academic research would better guide practice in an area showing remarkable growth in America, Asia, Europe, and the Middle East, with significant investments and valuations attached to it (Hirschberg et al., 2016). Notably, much of the $\mathrm{O} 2 \mathrm{O}$ literature focuses on consumer behavior toward online products and services in general; few studies address consumer attitudes and intentions toward OFDs. Topics covered in the existing literature include the influence of value systems on the decision to order from $\mathrm{O} 2 \mathrm{O}$ food delivery services (Roh and Park, 2019), the impact of e-service and food quality on customer loyalty toward OFDs (Suhartanto et al., 2019), the effect of drone food delivery on intentions (Hwang et al., 2019a), the influence of traffic conditions on significant performance indicators of OFDs (Correa et al., 2019), and evolutionary food quality (He et al., 2019). One theory-led examination of consumer attitudes and behavioral intentions toward OFD services relied on information-system theories of technology acceptance, a contingency framework, and the extended model of IT continuance (Yeo et al., 2017). The technology-adoption model and the elaboration likelihood model have been used to investigate consumers' decision-making while ordering food products through O2O commerce (Kang and Namkung, 2019a). Alagoz and Hekimoglu (2012) have also used the technology acceptance model to explore factors affecting the attitudes of Internet users toward OFDs. The unified theory of acceptance and use of technology (UTAUT) has been used to investigate the psychological factors that impact the use of mobile diet apps for ordering food online (Okumus et al., 2018).

In the context of FDAs specifically, there is scarce theoretical research on consumer behavior, and the studies available are primarily based on the application of technology acceptance theories, such as UTAUT 2 (Alalwan, 2020; Lee et al., 2019b), the technology acceptance model (Prabowo and Nugroho, 2019), and the extended technology acceptance model (Lee et al., 2017). To the best of our knowledge, few studies have invoked any seminal consumer behavior theories to examine consumers' responses to FDAs. For instance, Ray et al. (2019) have used the uses and gratifications (U\&G) theory to examine the behavioral disposition of consumers toward FDAs. Similarly, Kaur et al. (2020) examined the consumer resistance toward the use of FDAs. The shortage of broad consumer behavior research in 
the area limits the insights available to practitioners and researchers, as most available findings illuminate only the technology-related aspects of OFDs and FDAs.

An essential aspect of consumer behavior is the extent to which consumption values drive it. The theory of consumption values (TCV) proposed by Sheth et al. (1991) provides a formal theoretical lens for examining consumption values. Since its formulation in 1991, many scholars have applied the TCV to investigate consumer choice behavior. For example, Long and Schiffman (2000) used functional, social, emotional, epistemic, and conditional values to examine consumer behavior in the context of frequent-flyer programs. Zolkepli (2016) identified the influence of four consumption values - social, emotional, epistemic and conditional - on consumers' behavior related to the use of mobile apps. Reiterating the continued relevance of the TCV, recent studies have also employed it to examine consumer choice behavior. For instance, scholars have examined consumption values concerning online travel agencies (Talwar et al., 2020a); organic food consumption (Kushwah et al., 2019), halal holidays (Rodrigo and Turnbull, 2019), travelers' local food consumption (Rousta and Jamshidi, 2019), and various products from both online and traditional domains.

In the case of OFDs, the prior literature has contended that consumers' motivation to use these services is driven not only by convenience (Saarijärvi et al., 2014) but also by consumption values (Alavi et al., 2016), which are both utilitarian and hedonic (Nejati and Moghaddam, 2013). Broadly, the extant literature has acknowledged the usefulness of consumption values in understanding consumer behavior in the areas of hospitality and tourism (Jamrozy and Lawonk, 2017; Kim and Lee, 2017). This implies that the use of TCV in the context of FDAs will yield useful insights into related consumer behavior.

This discussion sheds light on three gaps in the existing research related to FDAs:

(1) Few studies have focused on consumer behavior toward OFDs in general and FDAs in particular.

(2) There is a dearth of theory-driven investigations in the context of FDAs.

(3) The choice behavior of consumers in terms of consumption values regarding FDAs has remained completely unexplored despite the established usefulness of the TCV in the hospitality literature.

The present study attempts to bridge these gaps by applying the TCV to understand consumer choice behavior in ordering food through mobile applications. The study examines three research questions (RQs):

$R Q 1$. Which consumption values influence purchase intentions toward FDAs?

RQ2. Are there any consumption values that can model consumer choice behavior in the specific context of FDAs?

RQ3. Are there any moderating influences of age and gender on the association between consumption values and purchase intentions?

To answer these research questions, we take the following three steps:

(1) undertaking a comprehensive literature review to understand prior research related to FDAs and TCV;

(2) contextualizing generic consumption values and adapting the TCV to FDA via an explorative mixed-method research approach - focus group discussions (FGDs) - for qualitative data collection and self-reported survey for quantitative data collection; and

(3) proposing and empirically testing research hypotheses on the association between consumption values and intentions.
Proposition of food delivery apps

1131 
IJCHM

33,4

1132

The novelty of this study comes from the following:

- It is the first to combine FDAs - an online service that it is attracting a lot of investment - and the TCV, which has continued to be one of the most relevant theories of consumer behavior since its formulation.

- It extends the TCV by adapting it to the FDA context with food consumptionrelated values, thus adding to the relatively scant literature on FDAs on the whole, which is essential, as FDAs represent the business model of new economy (i.e. O2O).

- This study is based on sample data from India, which is a growing but underresearched market from the FDA perspective.

- Finally, this work formulates a conceptual framework, the O2O TCV model, as the basis of future research on consumption values that drive intentions toward $\mathrm{O} 2 \mathrm{O}$ services in the hospitality sector.

The proposed model highlights that values driving the consumption of $\mathrm{O} 2 \mathrm{O}$ services stem not only from the technical merits and affordances of the apps but also from the actual use of the ordered products and services in offline settings. Thus, by including both the app-related values and those derived from the consumption of delivered food, the present study offers a framework for future studies to incorporate both these aspects (digital and physical) of the $\mathrm{O} 2 \mathrm{O}$ model within the broader domain of hospitality.

The rest of the article is structured as follows: Section 2 presents the background literature followed by details about how the TCV is extended to the FDA context in Section 3, model and hypotheses development in Section 4, and the methodology in Section 5. Section 6 presents the results of the analysis, Section 7 the discussion, and Section 8 the conclusion, implications, limitations and future research areas.

\section{Background literature}

\subsection{Food delivery apps}

FDAs enable consumers to search for and order food online to consume later in an offline location (Xiao and Dong, 2015). They help users conveniently see listed restaurants, menus and ratings, finalize and confirm orders via online payment, and track order statuses with no physical or telephonic interaction with restaurants. Research on what motivates consumers to order food through FDAs is vital for food retailers, particularly purchase intentions (Dodds et al., 1991), continuation intentions (Guo et al., 2018), dissatisfaction and satisfaction (Najmul Islam et al., 2017) and loyalty (Polites and Karahanna, 2012) are of high interest to service providers aiming to increase their market shares.

The studies in this area have primarily discussed the motives and technology-related aspects of FDAs. For instance, Yeo et al. (2017) examined the association of external factors with intentions toward OFD services and found an influence of perceived usefulness and ease of use on attitude toward technology adoption. The study also revealed that the intention to use OFD increased with improvement in the perception of post-usage usefulness and convenience. Similarly, Gunden et al. (2020) extended UTAUT 2 by including the impulse-buying tendency, congruity with self-image, and mindfulness to reveal that performance expectancy was a key driver of intentions to use online food delivery. Kang and Namkung (2019a) found that consumers' attitudes and behavioral intentions to use $\mathrm{O} 2 \mathrm{O}$ services for ordering food products are significantly impacted by information quality, perceived usefulness, perceived ease of use, source credibility, and customer trust. Lee et al. (2019b) extended UTAUT 2 to show that habit, performance expectancy, and social influence affect continuation intentions toward FDAs. Similarly, Lee et al. (2017) utilized an 
extended technology acceptance model to reveal that perceived usefulness and ease of use influence consumers' attitudes toward FDAs.

Some studies have transcended the technology adoption lens and used seminal behavioral theories to examine consumers' responses to FDAs. For example, Belanche et al. (2020) used the theory of planned behavior to reveal that consumers' attitude, behavior and subjective norms influenced their intentions to use and recommend FDAs. Similarly, Ray et al. (2019) applied the U\&G theory to reveal key gratifications associated with FDAs, such as delivery experience, convenience, customer experience and ease of use. The study found that customer experience, ease of use, and listing and searching for restaurants exerted significant influences on purchase intentions toward FDAs. Roh and Park (2019) confirmed the positive influence of usefulness and compatibility on the intention to use FDAs. In another recent study, Alalwan (2020) examined and confirmed that reviews, rating, and price influenced the intentions to reuse mobile food ordering apps. In a study linking the attributes of food-aggregator apps with consumers' purchase decisions, Kapoor and Vij (2018) examined four attributes: visual, navigational, information, and collaboration design. Single-person households were also more concerned about quality attributes represented by a variety of food choices, trustworthiness and price, while multi-person households were more concerned about convenience, trustworthiness and design (Cho et al., 2019).

Underscoring the geographical disparities in consumer behavior, Lee (2019) found that in Korea, the satisfaction of FDA consumers was driven by reliability, responsiveness, promptness, and food quality, whereas in China, cost-effectiveness, promptness, responsiveness, and food quality were more important. Also, for both countries, customer satisfaction positively correlated with repurchase intentions. Clearly, the consumer behavior research on FDAs and OFDs as a whole is still at an embryonic stage and is underrepresented in the literature (Correa et al., 2019). Further research is needed to provide insights into the barriers to and stimulators of success for FDAs, which are rapidly becoming a normal part of life. Analyzing consumer behavior from the perspective of consumption values can yield such insights. Examining consumer behavior toward technology-based advances is important from the perspective of hospitality sector as well. Prior studies have noted that with advances in digitization, consumers' habit and hedonic motivations related to information system have become key considerations in the hospitality domain (Morosan and DeFranco, 2019). Particularly, the use of mobile devices to access hospitality apps for a variety of purposes has made understanding customers' technological based interactions all the more important from the perspective of hospitality marketing (Litvin et al., 2018).

\subsection{Theory of consumption values}

2.2.1 Consumption values and intentions. Proposed by Sheth et al. (1991), the TCV is an approach to understanding the behavior of consumers in choosing products and services. It postulates consumer choice behavior based on five consumption values: functional, emotional, social, epistemic, and conditional values (Sheth et al., 1991, pp.160-163). Recently, scholars have utilized the TCV in the context of online products and services and in the hospitality sector to deepen insights into the association between consumers' intentions and consumption values.

Specifically, Peng et al.(2019) used the TCV to study the influence of perceived functional, hedonic, and symbolic/expressive values on consumers' satisfaction with restaurants at a travel destination, which subsequently affected consumers' attitudes and behavioral intentions toward the destination. Williams et al. (2017) examined the association between customer value, satisfaction and behavioral intentions among two culturally diverse groups 
IJCHM 33,4 of adventure tourists, one from Japan and another from Western countries. The study revealed that tourists from Japan give more importance to novelty and emotional values, whereas the Western tourists focused more on price value. In their study, Yang and Mattila (2016) argued that in the case of luxury restaurants, hedonic, functional, and financial values influence the intentions of consumers. Similarly, Kaur et al. (2018) found that social and emotional values partially influenced the continued use of online social media brand communities. Mäntymäki and Salo (2015) revealed that social and emotional values were the main factors influencing how teens spent real money in virtual worlds. Thus, the existing literature has underscored the relevance of the TCV in the context of both online products and services as well as in the hospitality sector, thereby supporting our choice of theory to model the drivers of consumer choice behavior toward FDAs.

2.2.2 Relevance of theory of consumption value in the food delivery application context. We justify our choice of the TCV for this study as follows. First, the choice of FDA is a manifestation of consumer behavior when faced with options, and the TCV is a commonly invoked theory in research for such purposes. For example, it has been used to investigate consumer choice behavior regarding green products (Lin and Huang, 2012) and smartphones (Bødker et al., 2009). Second, the TCV offers a sound way of understanding consumer behavior, as it combines the time-honored views on value in consumer-behavior research. Traditionally, consumer value has been described as subjective (Sinha and DeSarbo, 2006), the outcome of a cost-benefit tradeoff, and related to consumption experience (Holbrook, 1996). TCV determinants also cover all these aspects. Third, the TCV has been successfully extended to the online context to acquire insights into the value derived by consumers in digital and virtual worlds (Kaur et al., 2018; Mäntymäki and Salo, 2015). Finally, we have used the TCV to add to the research on consumer behavior in ecommerce, which is still evolving. This area is attracting a lot of attention, and recently, the focus of research has been online shopping experience to find ways to persuade customers to visit online shops and influence their intentions to purchase (Ho and Bodoff, 2014). Why customers prefer one outlet over another and what value they derive is not researched much in the contexts of e-commerce or m-commerce, particularly food apps. Hence, it is reasonable to presume that the TCV will be useful in understanding consumer value in the FDA context as well.

\section{Extending theory of consumption value to the food delivery application context}

\subsection{Exploring relevant consumption values}

Since the advent of the TCV, scholars have adapted its values to diverse contexts. For instance, Sweeney and Soutar (2001) expanded the theory by creating a measure named PERVAL to study the perceptions of consumers in the context of tangible products in retail. Further, while Sweeney and Soutar (2001) separated the functional value into quality and price, Kim and Eves (2012) measured functional value in terms of health in the hospitality and tourism sector. Gonçalves et al. (2016) and Lin and Huang (2012) revealed that in the context of green products, combinations of consumption values can be more relevant than a single generic value in explaining choice behavior. Perrea et al. (2015) adapted consumption values to incorporate the cross-cultural dimension and various gains and losses in the context of food products prepared using new food-processing technology. Similarly, Yang and Mattila (2016) identified hedonic, symbolic/expressive, and financial values as specific to the luxury segment of the hospitality industry. In consonance, the present study proposes to extend the TCV to the FDA context, considering not only app-related aspects but also aspects related to the actual product, that is, the food ordered using the app. 
In consonance with the efforts of scholars to adapt the TCV to specific contexts and extend it by proposing new values commensurate with those contexts, we have also attempted to adapt and extend the TCV to develop FDA-specific values. In this context, we undertook an extensive review of the TCV and FDA literature, which helped us form a view about the kind of consumption values a consumer may derive from using FDAs. Thereafter, to obtain the perspectives of consumers, we conducted a qualitative study in the form of FGDs. This helped us identify the consumption values that may be pertinent to FDAs. Since the TCV was our referent theoretical lens, we attempted to identify and map the FDAspecific values to the five TCV values: functional, emotional, social, epistemic, and conditional.

Toward this end, our literature review revealed that the TCV framework should be extended by incorporating general food-consumption concerns with no direct linkage with ordering from FDAs per se but that may impact consumers' purchase intentions. Accordingly, we introduce the cost of ordering from FDAs to consumption value, which is an aspect that can erode value. Perrea et al. (2015) also discussed the issue of costs in the context of values associated with food products prepared by novel processing technology. Calling it "performance risk," they linked it to the psychological ambiguity related to how a new product would fare, and this uncertainty was found to diminish consumption values related to the product in the study.

With FDAs, the existing literature and the issues gaining prominence in the media indicate that value erosion is likely to occur because of the problems associated with available and delivered food. In the past few years, in the debate surrounding challenges related to OFDs and FDAs, the concerns that have featured most prominently are food safety and quality. Issues commonly discussed in research and media reports are inconsistency in food quality and packaging (Dua, 2017), a rise in foodborne illnesses and tampering (Wasserstrom, 2018), and the delivery of low-quality food (Tandon, 2018). Food quality and safety and their implications for health have emerged as a grave issue in India, where the Food Safety and Standards Authority of India (FSSAI) has instructed leading FDA service providers (e.g. Swiggy, Zomato and others) to stop listing unlicensed restaurants (Tandon, 2018).

Scholars have also discussed food safety concerns in the context of out-of-home consumption by scholars. For instance, Liu and Lee (2018) found that food safety determined via human, functional, mechanical, and cleanliness factors positively influenced the satisfaction of consumers and their intentions to revisit a restaurant. Food safety has also been discussed in other contexts, such as food-safety violations (Harris et al., 2014), the food safety practices of food trucks (Okumus et al., 2019), foodborne illness outbreaks (Mun, 2020), and the food safety behavior of restaurant employees (Clark et al., 2019). A recent study underscored the issue of food safety concern by revealing the role of OFD platforms in transmitting foodborne diseases (Jiang et al., 2020). As the existing literature underscores food safety as a critical concern in food hospitality, we identify food-safety concerns as a value that may decrease the purchase intention toward FDAs.

In addition to food safety, recent literature has also highlighted health consciousness as a critical concern in food consumption. For instance, the inclusion of healthy, nutritional items on the menu for children increases parents' intentions to revisit a restaurant (Lee et al., 2016). Studies have discussed health consciousness in the context of improved food decisionmaking (Buhrau and Ozturk, 2018), the health halo effects of healthy foods (Her and Seo, 2017), and organic food choices (Shin and Mattila, 2019). Given that the existing literature supports health consciousness as a critical factor in food choice behavior, we also identify it as a value that may affect purchase intentions toward FDAs. Furthermore, we posit that it 
IJCHM

33,4

has a negative value because public discussion and actions surrounding the safety of FDAdelivered food may dissuade health-conscious consumers from ordering food through these aggregators.

Given this background, in this study, health consciousness and food safety concerns have been identified as possible constructs that may better capture the multidimensional nature and undesirable aspects of the consumption values of FDAs. This is consistent with studies that have emphasized the importance of health benefits, hygiene, and safety issues in the context of food consumption by tourists (Choe and Kim, 2018) and their purchase intentions toward organic food (Shin et al., 2018). The same also emerged from the discussions on the qualitative study, discussed below.

\subsection{Focus group discussions}

In the absence of a reference for adapting consumption values to FDAs or OFDs, we have used FGDs to identify relevant values, map them to the generic TCV framework, and adapt the existing scales to develop the relevant measures. This was necessary because there were none a priori, and the present study aims to extend the theory. FGDs were also used because we did not want our literature review or our views on FDAs to influence the study model or outcomes. The literature broadly acknowledges that FGDs are exploratory and yield themes beyond researchers' pre-determined concepts (Krueger and Casey, 2009). To summarize, we selected a focus group approach for the following reasons:

- This study presents the first extension of the TCV to FDA.

- While food-related concerns are theoretically meaningful and empirically supported in related contexts, they have not been tested with FDAs.

- Owing to cultural differences, consumer opinions in a specific region of study are important to contextualize the TCV scales to the FDA context.

3.2.1 Focus group discussion participant selection. Consistent with the objectives of the study, the FGD participants had to be active FDA users, with a relevant app installed on their phone and having used it at least once every two weeks in the six months preceding the FGD. We formed four focus groups (4-6 people per group) with 20 FDA users (14 male and 6 females) based in India. We also aimed to have at least one and not more than two female participants from among housewives aged 25-50 years (to cover young as well as full-nest households) in each group. At least one participant in each group was selected from among people with exposure to food-related concerns in a professional capacity (e.g. doctors, restaurant employees, academicians, etc.) aged 22-61 years. The rest were chosen to adequately represent young adults and adults to mix profiles based on other demographic factors, such as educational qualification, income, and gender. To ensure that all aspects were discussed, we introduced one additional recruitment criterion: at least one participant in each group had to have posted two negative reviews on their FDA's feedback page in the six months preceding the FGD to ensure that the groups also focuses on negative aspects and continued usage despite negative reviews.

The FGDs were conducted in October 2019, and the discussions lasted for 20-30 minutes each in both Hindi and English. Two researchers moderated the discussions and took notes. The participants were asked to discuss their experiences (both positive and negative), perceptions, and viewpoints about using FDAs. The discussions focused on participants' understanding of the possible inhibitors and motivators of using FDAs and the issues related to ordering food online, the use of mobile applications for ordering food, and concerns related to food consumption that could influence the retail food-ordering intentions 
of consumers. We analyzed these qualitative insights using the grounded theory approach (Glaser and Strauss, 1967).

3.2.2 Mapping the theory of consumption values to food delivery applications. We used the insights obtained from the FGD to adapt the generic consumption values to the FDA context. First, functional value, which is defined as the utility that consumers perceive to derive from the features and physical performance of a product or service offering, was mapped to be measured through price value, health consciousness (which refers to health value), and food-safety concerns (which refer to quality value). This is consistent with prior TCV literature that has captured functional value through price, health, and quality (Gonçalves et al., 2016; Kim and Eves, 2012).

In the generic context, social value is related to the image that an individual wants to present to social groups through his/her choice behavior. The participants of the FGDs conducted by the present study thought that the use of FDAs seemed to change how others perceived them. The discussion also revealed that using FDAs gave the users pleasant feelings and helped them stand out among their peers. Overall, the participants felt it "socially prestigious" to use FDAs. Drawing on the connections that emerged between social settings, self-image, and the prestige the users associated with using FDAs, we used the name "prestige value" to represent social value in the FDA context. This is also in consonance with the view expressed by Williams and Soutar (2009) that the prestige an individual gains from his/her travels is related to social value. Notably, social value is normally context-specific, implying that the study location may play a role in determining how social value is perceived. Perception can also be expected to depend on the economic development of an area.

With reference to the classical TCV proposition, conditional value is driven by certain extrinsic factors, such as the quality of life associated with a product or service that may influence the choice behavior toward it. During the FGDs conducted for the present study, the participants frequently mentioned that they would use a particular FDA if the delivery time was short, the cost was low, a competitive promotional incentive was offered, and if their preferred restaurants were listed on that FDA. Since these seem to be extrinsic factors that could improve FDA usage value for consumers, we mapped these to the generic conditional value and named it "affordances value" in the FDA context, borrowing the word affordance from the social media literature, where studies have use the term to denote the merits or advantages of social media platforms (Dhir et al., 2017). By doing so, we wanted to capture and underscore how the consumption value derived from FDA use can be enhanced if they offer certain extrinsic advantages.

Epistemic value is related to the ability of a product or service to offer novelty and stimulate curiosity. During the FGDs, the participants referred to their curiosity about FDAs because they saw many people using them and found them novel. Since the participants felt that others were availing the benefits of FDAs, they searched for more information about them. Since these aspects are related to the classical conceptualization of epistemic value, we identified epistemic value as a consumption value associated with FDA use. Our review of literature and FGDs also revealed that visibility - use of the application by others and advertisements - was an important factor in the e-commerce domain that influenced intentions (Johnson et al., 2018). In light of this description, we used the term "visibility," which is a source of information for potential FDA users via advertisements and the usage behavior of other users to represent epistemic value in the FDA context.

Thus, in the present study, FDA-specific values represent the generic functional value: price, health consciousness, and food-safety concerns. Similarly, prestige captures social value, affordances capture conditional value, and visibility captures epistemic value. Table 1 
IJCHM

33,4

\begin{tabular}{ll}
\hline Generic TCV values & FDA-specific values \\
\hline Functional value & Price
\end{tabular}

Operational description

Health consciousness

\section{8}

Food-safety concern

Social value Prestige

Conditional value Affordances

Epistemic value Visibility

Table 1.

Variable descriptions

The value for money and benefits that FDA users perceive they derive by ordering food that is reasonably priced

The concerns that reduce health-conscious consumers' health value if they perceive that food ordered from FDAs is not healthy The erosion of quality value due to concerns about the safety of food ordered from FDAs

The boost in self-image that consumers derive in their social settings by ordering food from FDAs

The features, advantages, or merits that drive value derived by consumers when they order food from FDAs, which include certain conditions, such as listing of preferred restaurants, that may enhance consumption value derived from FDA use The feeling of curiosity and novelty incited by seeing others use FDAs, which can increase the value derived from using FDAs

presents the operational descriptions of all the FDA-specific values identified and mapped to the TCV by the present study.

\section{Model and hypotheses development}

The proposed TCV-based framework examines the association between consumption values as the antecedents of purchase intentions toward buying food via FDAs (Figure 1). The independent variables are functional (price, health consciousness, and food safety concerns), social (prestige), conditional (affordances), and epistemic (visibility) values. The study also examines the moderating role of age and gender on the association between consumption values and purchase intentions. Economic background and educational qualifications are the control variables, as the prior literature suggests that budgetary constraints influence consumer decisions (Bernini and Cracolici, 2015) and because foodrelated behaviors are particularly affected by household income (Di Talia et al., 2019).

\subsection{Functional value (price, health consciousness, and food safety concerns)}

Functional value is the utility that consumers perceive to derive from the features and physical performance of a product or service offering. Scholars have examined it in the context of intentions toward food choices as well as food tourism (Choe and Kim, 2018; Jamrozy and Lawonk, 2017). Scholars have found a positive association between functional value and use intentions (Kim et al., 2018a, 2018b). Previous food-related studies have typically taken functional value to represent quality, price, and health (Kim and Eves, 2012; Perrea et al., 2015). This study also uses these three aspects - price, health and quality - to capture functional value in the context of FDAs.

Some studies have discussed the key influence of functional features on consumers' intentions and attitudes. For instance, Yeo et al. (2017) suggested that the money-saving 


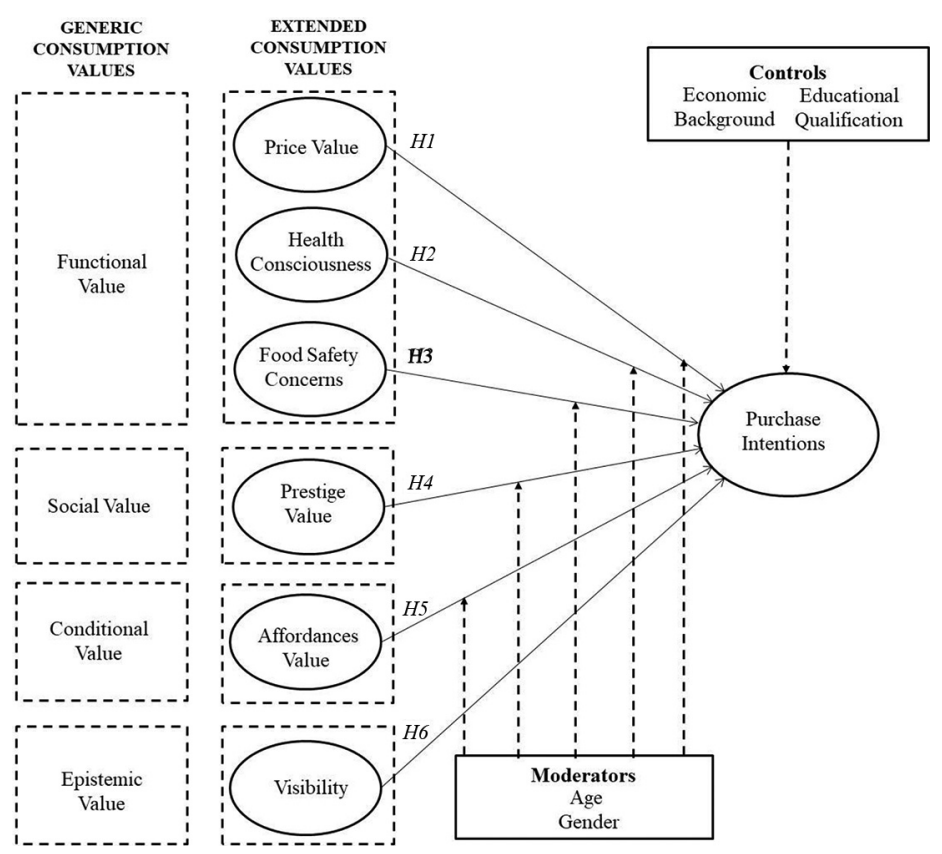

Proposition of food delivery apps

1139

Figure 1.

Proposed research model

aspect of OFDs influences customers' perceptions of usefulness and their continuation intentions. Other studies have identified price as important for intentions toward ordering food online (Alalwan, 2020; Cho et al., 2019). Even though the TCV has not been extended to study consumer behavior toward FDAs, functional value can be expected to have a strong impact on FDA usage through the price aspect, so we propose it as an antecedent of intentions. Drawing on published findings, we measure price value in the present study through benefits offered, price reasonability, and value for money. The price value should enhance purchase intentions toward FDAs. Hence, we propose the following hypothesis:

H1. Price value positively correlates with customers' intentions toward FDAs.

The second measure of functional value is health consciousness, which is related to health value. Health consciousness represents the willingness of individuals to make decisions and actions related to their health (Lee et al., 2014). The choice of the health aspect in this study is consistent with previous studies on the TCV and food choices (Choe and Kim, 2018), which have considered health value as a part of functional value. This choice is also supported by prior literature that has linked health with consumer food choices in general (Dubé et al., 2016).

As discussed previously, FDAs have been facing multiple food-related challenges (Wasserstrom, 2018), which might dissuade health-conscious consumers from ordering food through them. In other words, food delivered by FDAs arguably creates negative health value, as it may not be perceived as a healthy food choice. In line with the extant literature linking food choices to health consciousness, health-conscious consumers will likely derive negative health value from FDAs. Thus, it is likely that health consciousness will erode purchase intentions toward FDAs. Hence: 
IJCHM 33,4

H2. Health consciousness, representing health value, negatively correlates with customers' intentions toward FDAs.

The third functional value is the quality that consumers can derive from ordering food using FDAs (Kim and Eves, 2012). Food quality is a key driver of loyalty toward OFDs (Suhartanto et al., 2019), and the same can be expected for FDAs. Food safety is an important aspect of food quality. Food safety implies minimizing hazards that may lead to harm or illness when food is consumed (World Health Organization, 2015) or even death (Maberry, 2016). In fact, food safety culture has become an important aspect of the food supply chain (Nayak and Waterson, 2017), as poor safety culture can undermine brands (Hussain and Dawson, 2013). The present study measures quality in terms of food safety concerns, a term derived from prior literature on food (Liu and Ma, 2016). Since the outcome of FDA usage is food consumption, we anticipate that concern for food safety will play a key role in purchase intentions toward FDAs. Consumers with great concern for safety are likely to derive less quality value from FDAs, which often appear in the news for food safety concerns (Tandon, 2018). Thus, it is likely that concern for food quality and safety will dissuade consumers from using FDAs. Accordingly, we propose the following hypothesis:

H3. Food safety concern, representing quality value, negatively correlates with customers' intentions toward FDAs.

\subsection{Social value (prestige)}

Social value is associated with the image that consumers want to project among their social groups through their choice behavior (Elliot et al., 2011). Though no one has discussed social value in the context of FDAs previously, studies have discussed the positive association between social value and intentions in the context of hospitality and tourism. For example, social value is associated with customer intention to use applications to book hotel stays (Morosan and DeFranco, 2016). It also represents the prestige and recognition that individuals gain from their travels (Williams and Soutar, 2009), from local food consumption at travel destinations (Mak et al., 2012), and from sharing their travel experiences with their social groups (Chang et al., 2010). Consumers also derive social value from the prestige they perceive in dining at a starred restaurant (Kim and Lee, 2017).

In the present study, social value represents the prestige and self-image boost consumers derive in social settings by using FDAs. In relation to FDA use, social value implies gaining social approval, making a positive impression, and appearing to be smart by using the latest technology, so we have christened it prestige value in the FDA context. We estimate that FDA users will derive prestige value from using FDAs, which will stimulate their purchase intentions. Thus, we propose the following:

H4. Prestige value, representing social value, positively correlates with customers' intentions toward FDAs.

\subsection{Conditional value (affordances)}

Conditional value is defined as the value that consumers derive from certain extrinsic factors, such as the quality of life offered by a chosen alternative (Gómez et al., 2018). Like social value, no one has discussed conditional value in the context of FDAs. However, scholars investigating aspects of hospitality and tourism have found a relationship between conditional value and consumer choice behavior. For instance, conditional value positively 
drives the choice of a vacation destination (Phau et al., 2014). Furthermore, tourists tend to perceive conditional value as a key value in travel-related decision-making (Hur et al., 2012). In the context of mobile apps, which are closely linked to FDAs, prior studies have reported a significant influence of conditional value on consumer decision-making (Zolkepli, 2016).

Based on these findings, the present study also anticipates a positive association between conditional value and intention toward FDAs. Here, conditional value is measured by the presence of conditions such as free delivery or at least reduced delivery charges, better promotional incentives, lower delivery time, and listing of preferred restaurants. It is likely that conditions such as free and fast delivery and promotional offers positively influence users' intentions to order from FDAs. As discussed before, these items represent affordances, that is, the advantages or merits available when FDAs are used to order food. In other words, they represent the conditions that may induce a user to have positive intentions toward FDAs. Thus, we rechristen this value as affordances value in the FDA context, and we propose that:

H5. Affordances value, representing conditional value, positively correlates with customers' intentions toward FDAs.

\subsection{Epistemic value (visibility)}

Epistemic value denotes the ability of a product or service to incite curiosity, offer a sense of novelty, and/or satisfy information search instincts (Choe and Kim, 2019; Wong et al., 2019). Studies have found a positive association between epistemic value and choice behavior in domains such as health food (Thomé et al., 2019) and tourism destinations (Ashton, 2015). This study measures epistemic value in terms of visibility, which reflects the nature of mobile apps like FDAs. Research on information systems has shown that visibility - seeing others use an innovation-increases the adoption intention of the observer (Johnson et al., 2018).

In this study, visibility is measured to represent informational aspects, such as promotional advertisements, the feeling of curiosity incited by seeing others use the FDA, and the sense of novelty of a technology-driven product whose benefits are being enjoyed by others. Thus, it arguably represents epistemic value. Based on prior studies, we anticipate that epistemic value (visibility) will enhance intentions to use FDAs. Hence, the present study proposes the following hypothesis:

H6. Visibility, representing epistemic value, positively correlates with customers' intentions toward FDAs.

\subsection{The moderating role of age and gender}

Scholars have discussed the role of moderating variables to explain individual differences in consumer behavior (Meyers-Levy and Loken, 2015; Hwang et al., 2019b). Scholars have examined demographic variables, particularly age and gender, as moderating variables in multiple contexts. For example, Tan and Ooi (2018) found that gender and age moderate the purchase decisions of tourism products through mobile apps. Similarly, Ye et al. (2017) identified the moderating influence of age on the association between premium price payment, social website, and intentions toward online travel agencies. Worsley et al. (2013) found gender-based differences in food safety concerns. Given the above discussion, we expect that the age and gender of the users will moderate the association between consumption values and intentions toward FDAs. Therefore, we propose the following: 
IJCHM

33,4

\section{2}

H7. The relationship between consumption values and purchase intentions toward FDAs will be different for users in different age groups.

H8. The relationship between consumption values and purchase intentions toward FDAs will be different for males and females.

\section{Methodology}

\subsection{Data collection}

We developed the survey instrument used for data collection from the FGDs and existing validated scales, and we piloted the instrument among 20 FDA users in India. The results of the pilot survey helped introduce minor corrections in the wording of questions to ensure clarity. The final questionnaire was administered to FDA users using the mall intercept method, interviewers intercepting respondents at the entries and exits of malls, which Yani-de-Soriano et al. (2019) adopted to minimize sampling bias, reach out to a mixed profile of respondents, and select potential survey participants eligible per the screening criterion: that the respondents used an FDA at least once a week for three months preceding the FGD. Surveys occurred in malls in four metro cities in India from November-December 2019. A total of 423 valid responses were considered after discarding incomplete responses. Before administering the survey, the participants received briefing about the background of the project and assured of the anonymity of their information. The minimum age of participants was 18 years, and the maximum was 63, with a mean of 27.14. Table 2 gives other demographic details of the participants.

No FDA sampling frame using the Indian population is available, so the non-probability judgmental sampling was used following prior studies (Leong et al, 2020). The use of FDAs has proliferated in India, with user penetration reaching $7.5 \%$ in 2020 and being expected to rise to $10.9 \%$ by 2024 (Statista, 2020).

\subsection{Data analysis}

We analyzed the data using a two-step approach in IBM SPSS and AMOS. First, confirmatory factor analysis (CFA) was performed to ascertain the reliability and validity of the measures. Thereafter, structural paths were analyzed to evaluate the hypotheses. We conducted moderation analysis in the Process macro. The choice of SEM as a data-analysis method is justified because the study tests hypotheses grounded in a strong theoretical framework, following Hew et al. (2019). Supporting the suitability of SEM, the collected data also meet the multivariate requirements for such an analysis, which implies that the

Table 2.

Demographic profiles of participants

\begin{tabular}{llcr}
\hline Variables & Category & Frequency & (\%) \\
\hline Gender & Female & 156 & 36.9 \\
& Male & 267 & 63.1 \\
Economic Background & More than 2.5 million to 3.5 million & 18 & 4.3 \\
(Annual income in INR) & More than 1.5 million to 2.5 million & 210 & 49.6 \\
& Half million to 1.5 million & 163 & 38.5 \\
& Less than half million & 32 & 7.6 \\
Educational Qualification & High school only & 20 & 4.7 \\
& Graduate degree & 199 & 47.0 \\
& Master's degree & 188 & 44.4 \\
& Doctoral degree & 16 & 3.8 \\
\hline
\end{tabular}


collected data are normally distributed and have no multicollinearity issues (Kock and Lynn, 2012). Due to the self-reported nature of data, common method bias (CMB) could be a concern (Podsakoff et al., 2012), which was tested for using a Harman one-factor test.

\section{Results}

\subsection{Multicollinearity}

Before the CFA, data were tested for the presence of multicollinearity effects. Toward this end, we examined the variance inflation factors (VIFs) and tolerances. The results revealed that the values of VIFs were less than 10 and tolerances were greater than 0.10 , which confirmed the absence of multicollinearity, as discussed by prior studies (Hew and Kadir, 2016).

\subsection{Common method bias}

Since the data from all the variables came through the same instrument, there is a risk of $\mathrm{CMB}$. To check whether this problem existed in our data, we used Harman's single-factor test (Harman, 1976), consistent with prior studies (Talwar et al., 2020b). The results revealed that a single factor explained $34.32 \%$ of the overall variance, which was less than $50 \%$.

\subsection{The measurement model}

We conducted CFA to evaluate the validity and reliability of the measures. The results showed satisfactory goodness-of-fit indices $(\chi 2 / d f=2.69, C F I=0.94, N F I=0.90, T L I=$ 0.93, RMSEA $=0.06$ ) (Anderson and Gerbing, 1988). Item reliability was also confirmed since all factor loadings were above 0.70 , except four items whose loadings were in the range of 0.6, which is within the acceptable cutoff of 0.50 (Hair et al., 2016) (Table 3).

The convergent validity criteria recommended by Fornell and Larcker (1981) - a composite reliability (CR) score greater than 0.7 and an average variance extracted (AVE) greater than 0.5 - were also supported by the model (Table 4). Finally, the square root of the AVE for each construct exceeded the correlations between the constructs, confirming discriminant validity. Additionally, the correlation between the investigated constructs was less than the suggested threshold value of 0.80 , which further confirmed discriminant validity.

\subsection{The structural model}

Structural path analysis returned satisfactory model fit indices $(\chi 2 / d f=2.65, C F I=0.92$, $N F I=0.87, T L I=0.90$, RMSEA $=0.06$ ), confirming the goodness of fit. Figure 2 summarizes the hypotheses testing, which supported $H 1, H 4, H 5$, and $H 6$; that is, price value $(\beta=0.19$, $p<0.001)$, prestige value $(\beta=0.13, p<0.001)$, affordances value $(\beta=0.37, p<0.001)$, and visibility $(\beta=0.47, p<0.001)$ were positively associated with the purchase intention toward FDA. Health consciousness $(\beta=-0.09, p>0.05)$ and food safety concern $(\beta=0.02$, $p>0.05)$ were non-significant correlates. The developed model explained $76.7 \%$ of the variance in purchase intentions toward FDAs.

\subsection{Moderation analysis}

We conducted moderation analysis using the Process macro model 1. The results showed that age did not moderate the association of purchase intentions with price value $\left(\mathrm{PE}_{\text {interaction }}=0.004,95 \% \mathrm{CI}[-0.0079,0.0161]\right)$, prestige value $\left(\mathrm{PE}_{\text {interaction }}=0.01,95 \% \mathrm{CI}\right.$ $[-0.0339,0.0187])$, health consciousness $\left(\mathrm{PE}_{\text {interaction }}=-0.01,95 \% \mathrm{CI}[-0.0287,0.0046]\right.$ ), affordances value $\left(\mathrm{PE}_{\text {interaction }}=0.001,95 \% \mathrm{CI}[-0.0101,0.0192]\right)$, and visibility $\left(\mathrm{PE}_{\text {interaction }}=\right.$ $-0.002,95 \%$ CI $[-0.0145,0.0100])$. However, age negatively moderated the association of food- 
\begin{tabular}{l} 
IJCHM \\
33,4 \\
$\mathbf{1 1 4 4}$ \\
\hline
\end{tabular}

Table 3.

Results of confirmatory factory analysis

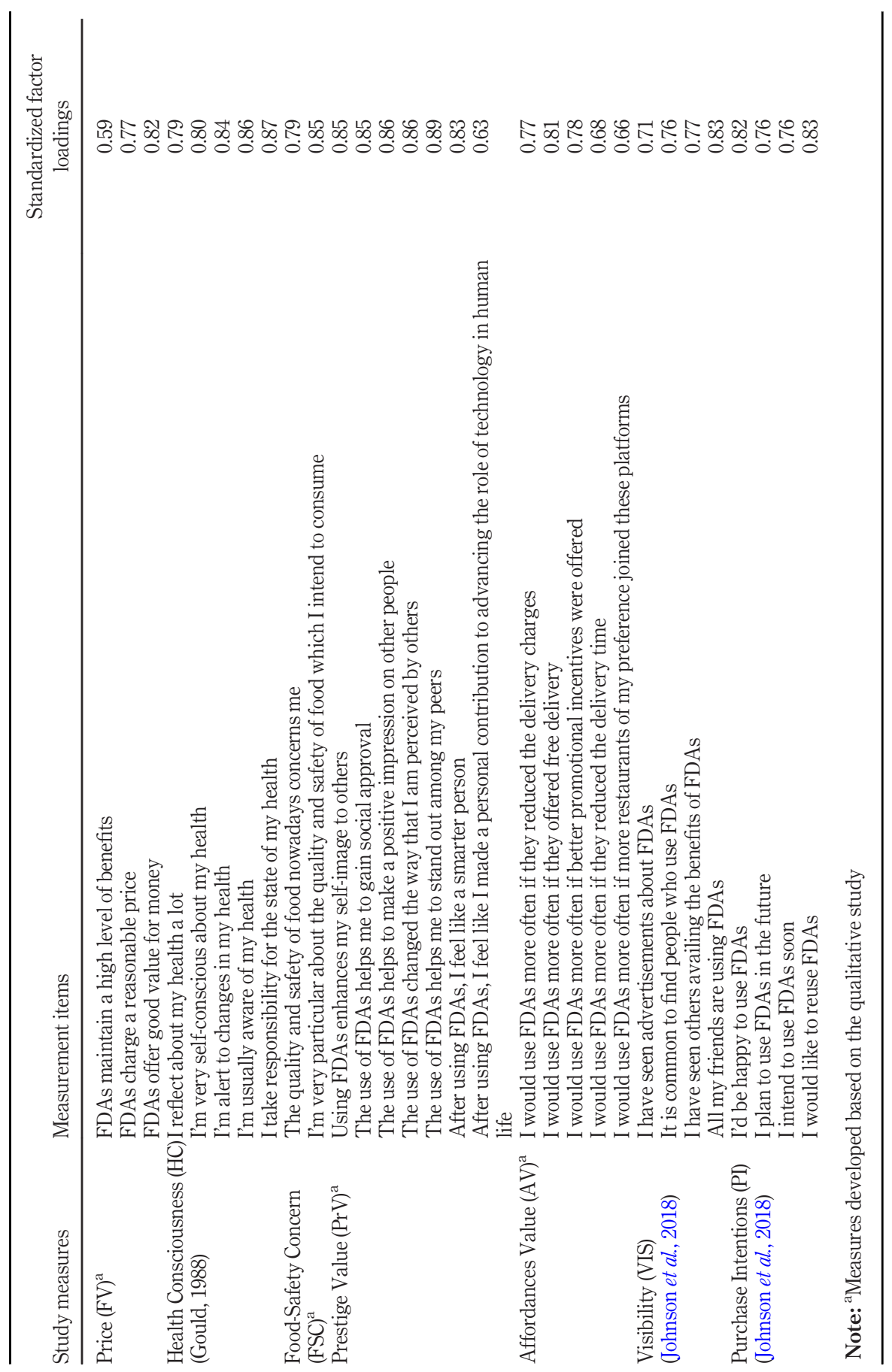


safety concerns and purchase intentions $\left(\mathrm{PE}_{\text {interaction }}=-0.01,95 \% \mathrm{CI}[-0.0268,-0.0006]\right)$. A deeper exploration of the moderating influence of age revealed that young users exhibited lower purchase intentions and older users higher intentions (Figure 3). However, in the case of high food-safety concerns, the older users exhibited lower purchase intentions and young users higher intentions (Figure 3).

In contrast, gender did not moderate the relationship of purchase intentions with any of the consumer values, that is, price value $\left(\mathrm{PE}_{\text {interaction }}=0.06,95 \% \mathrm{CI}[-0.1145,0.2309]\right)$, prestige value $\left(\mathrm{PE}_{\text {interaction }}=-0.04,95 \%\right.$ CI $\left.[-0.1951,0.1101]\right)$, health consciousness $\left(\mathrm{PE}_{\text {interaction }}=0.15,95 \% \mathrm{CI}[-0.0533,0.3450]\right)$, food-safety concern $\left(\mathrm{PE}_{\text {interaction }}=0.13,95 \%\right.$ $\mathrm{CI}[-0.0464,0.3052])$, affordances value $\left(\mathrm{PE}_{\text {interaction }}=-0.05,95 \% \mathrm{CI}[-0.2026,0.1100]\right)$, or visibility $\left(\mathrm{PE}_{\text {interaction }}=-0.10,95 \% \mathrm{CI}[-0.2512,0.0605]\right)$.

\subsection{Control variables}

Prior studies have found that control variables can improve the robustness of findings and have used various demographic variables as controls (Talwar et al., 2020c). Accordingly, the proposed model was controlled for two demographic variables - economic and educational backgrounds - both of which had no influence on purchase intentions toward FDAs (economic background: $\beta=0.02, p>0.05$; educational background: $\beta=0.06, p>0.05$ ). This implies that the economic and educational backgrounds of consumers do not confound the study variables significantly.

\section{Discussion}

The results of the study support $H 1, H 4, H 5$ and $H 6$, revealing that price, prestige, conditional, and visibility values have significant positive associations with purchase intentions toward FDAs. The results of the data analysis confirmed the positive association between price value and purchase intentions toward FDAs (H1). H1 proposed that FDAs must maintain a high level of benefits, charge reasonable prices, and offer good value for money to positively influence the purchase intentions of customers. The results imply that FDAs must maintain a steady flow of benefits, such as discounted membership, freebies for orders beyond a certain value, and special discounts for frequent users to enhance the price value derived from FDA use. Such increased price value, in turn, positively influences intentions toward FDA use. This finding is consistent with those of earlier studies (Alalwan, 2020; Cho et al., 2019). It has also been discussed anecdotally that consumers ordering through FDAs are mostly price-sensitive and are seeking a price advantage.

\begin{tabular}{lccccccccccc}
\hline & CR & AVE & MSV & MaxR(H) & FSC & PV & PrV & AV & PI & VIS & HC \\
\hline FSC & 0.81 & 0.68 & 0.67 & 0.81 & 0.82 & & & & & & \\
PV & 0.77 & 0.54 & 0.37 & 0.80 & 0.15 & 0.73 & & & & & \\
PrV & 0.94 & 0.69 & 0.18 & 0.95 & 0.04 & 0.43 & 0.83 & & & & \\
AV & 0.86 & 0.55 & 0.51 & 0.87 & 0.45 & 0.42 & 0.28 & 0.74 & & & \\
PI & 0.88 & 0.65 & 0.51 & 0.88 & 0.31 & 0.61 & 0.38 & 0.72 & 0.80 & & \\
VIS & 0.85 & 0.59 & 0.50 & 0.86 & 0.49 & 0.41 & 0.12 & 0.61 & 0.70 & 0.77 & \\
HC & 0.92 & 0.69 & 0.67 & 0.92 & 0.82 & 0.22 & 0.18 & 0.42 & 0.31 & 0.42 & 0.83
\end{tabular}

Notes: Composite reliability $=\mathrm{CR}$, Average variance extracted $=\mathrm{AVE}$, Maximum shared variance $=\mathrm{MSV}$, Average shared variance $=$ ASV, Price Value $=$ PV, Prestige Value $=$ PrV, Affordances Value $=$ AV, Food Safety Concern $=$ FSC, Health Consciousness $=$ HC, Visibility = VIS, Purchase Intentions = PI; values in diagonal (and italic) are the square roots of AVE
Proposition of food delivery apps

1145

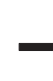


IJCHM

33,4

\section{6}

\section{Figure 2.}

Results of hypotheses testing
Figure 3.

Graphical representation of moderating influence of age
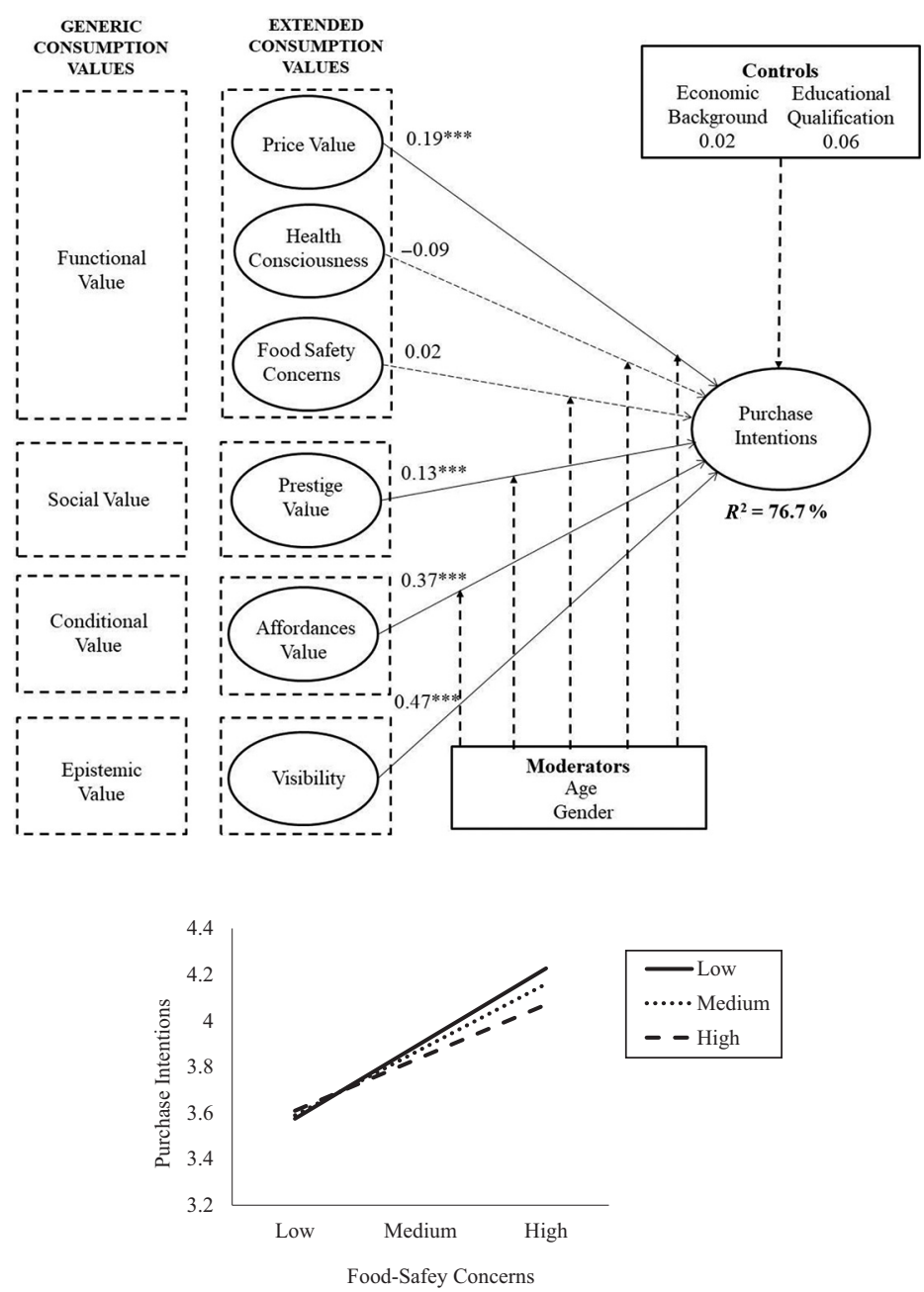

$H 2$ and $H 3$, which proposed the negative associations of health and quality values (parts of the generic functional value) with purchase intentions, found no support in the findings. This study measured health value through health consciousness and quality value through food-safety concerns. This finding was not anticipated based on past reports of health and food-safety concerns raised in the case of FDA-delivered food (Wasserstrom, 2018; Tandon, 2018). One possible reason for such a result is that users choose restaurants to order from on FDAs only after reading reviews and checking ratings. Studies have confirmed that online reviews influence online purchases (Casaló et al., 2015), so the contention that reviews may help FDA users choose restaurants known to deliver safe food is quite plausible. Another explanation is that food is ordered through FDAs for convenience, especially when the alternative of cooking at home is not possible because of time and facility constraints. In such situations, users may tend to overlook health and quality. Despite these arguments, no 
firm conclusion can be drawn, and more studies are required to provide deeper insights into whether consumers think of health and food safety concerns while ordering food on FDAs. This is particularly important since health and food safety are key concerns and known to be key issues in food choices (Dubé et al., 2016), and the latest studies have also linked online food delivery with the spread of foodborne diseases (Jiang et al., 2020). In summary, since these variables have not been explored much in the context of FDAs and the present study is simply an initial attempt to consider these variables, further research with more diverse samples drawn from different geographies is required to confirm if this result is a function of the sample. Furthermore, considering various demographic influences, such as income level or food interest, may supply more insights into these findings.

H4, which proposed the positive influence of social value associated with purchase intentions from FDAs, found support. The results suggest that customers perceive prestige and enhanced self-image in ordering food from FDAs. This result agrees with that of earlier studies on food consumption, where individuals associate prestige with where they dine (Kim and Lee, 2017). The result also confirms that from the perspective of Indian consumers, FDAs serve as a source of enhancing social perception and making positive impressions by using the latest technology to order food, thereby increasing their consumption value measured as prestige value. The value so derived will, in turn, increase their intentions to use FDAs. The same behavior may not be shown by consumers in a different cultural setting. For instance, consumers in Western countries may derive social value from the use of FDAs as a quick, easy way to order preferred food items when friends are together, leaving them more time to bond, communicate, and have fun. More studies are necessary to examine the association between consumption values and intentions to use FDAs. Since our study is the first attempt to empirically examine social value in the context of FDAs, it provides a foundation for researchers to identify consumption values that consumers in different countries associate with FDAs.

$H 5$, proposing the positive relationship of affordances value with purchase intentions toward FDAs, found support in the results of the data analysis. This finding conforms with the findings of other studies on consumption values that found conditional value to positively drive the choice behavior of consumers (Hur et al., 2012; Phau et al., 2014). Positive association implies that conditions such as free delivery or low delivery charges, promotional incentives, fast delivery, and listing of good restaurants are likely to increase the consumption value that users derive from FDAs and enhance their intentions to order food on them. Support for this hypothesis indicates that FDA consumers are more likely to order for food from FDAs that offer better deals in terms of not only delivery but also the quality and the type of restaurants listed.

H6 hypothesized a positive relation between epistemic value (measured as visibility) and purchase intention toward FDAs. In fact, visibility had the strongest influence on purchase intentions of food via FDAs, meaning that epistemic value is positively linked with purchase intentions toward FDAs. Thus, advertisements and curiosity stemming from observing others use FDAs can positively impact customers' intentions to order food on FDAs. A positive association between epistemic value and choice behavior was in fact confirmed by Thomé et al. (2019). Support for this hypothesis indicates that users are more likely to order food from FDAs if they see their friends and acquaintances do the same. The finding also suggests that advertising may lead to increased positive intentions to order food from FDAs and reinforces the fact that in e-commerce, external influences in the form of observing others using apps/sites to buy/order products or services motivates consumers and influences their choice behavior (Johnson et al., 2018). 
$\mathrm{IJCHM}$

33,4

\section{Conclusion, implications, limitations and future research areas}

\subsection{Conclusion}

This study attempts to augment the research on consumer behavior in the context of intentions to order food via FDAs. Given its online context, the study is important from the perspective of hospitality sector, since scholars have argued that it is critical to understand varied aspects of consumer engagement during the online purchase of hospitality services and products (Morosan and Bowen, 2018).The study invoked the TCV, a longstanding theory of consumer choice behavior, to propose and answer three research questions. To address RQ1 and RQ2, which were related to the consumption values that influence purchase intentions toward FDAs, we undertook an extensive review of the literature and conducted a qualitative study using FGDs. This step helped us identify and map FDAspecific consumption values to the classical TCV framework. The identified FDA-specific values are health consciousness, food safety concerns (representing the generic functional value), prestige value (representing the generic social value), affordances value (representing the generic conditional value), and visibility (representing the generic epistemic value). The results of data analysis in SEM revealed that epistemic value (visibility) was the chief driver of purchase intentions toward FDAs, followed by conditional (affordances), price (part of the functional value), and social (prestige) values. Food-safety concerns and health consciousness (proposed as part of the functional value) did not seem to share any statistically significant associations with purchase intentions toward FDAs.

To address $R Q 3$, we tested the moderating influence of age and gender on the association between consumption values and purchase intentions using the PROCESS macro. Both demographic variables had no moderating influence, except for age moderating the association of food-safety concerns with intentions. Likewise, both the control variables economic and educational backgrounds - did not confound the proposed linkages in the study. The study thus offers several useful implications for theory and practice.

\subsection{Theoretical implications}

The five key theoretical contributions of this work are as follows. First, the main contribution of this work is the $\mathrm{O} 2 \mathrm{O}$ TCV model, which is applicable in various contexts (Figure 4). The model suggests that in $\mathrm{O} 2 \mathrm{O}$ contexts, consumption values must be bifurcated into two broad categories:

(1) App-related features, such as listings and visibility; and

(2) Consumption of the ordered product or service in the offline venue.

The model in Figure 4 comprises the following components:

- App-specific values: The model in Figure 4 includes the values based on our study and the scope of more values specific to the target $\mathrm{O} 2 \mathrm{O}$ service (under the heading "miscellaneous"). For instance, some app-specific values in tourism-related O2Os can be derived from e-service quality, review authenticity, and source credibility. However, further qualitative studies are necessary to identify values specific to the contexts of particular $\mathrm{O} 2 \mathrm{O}$ services.

- Product/service-specific values: These values are related to offline consumption or the use of a product/service ordered online. The model again provides a scope for the inclusion of values specific to the target $\mathrm{O} 2 \mathrm{O}$ service under the heading "miscellaneous." Some product/service-specific values in the context of tourismrelated $\mathrm{O} 2 \mathrm{Os}$ can be hedonic, safety, privacy, interaction, and emotional. However, 


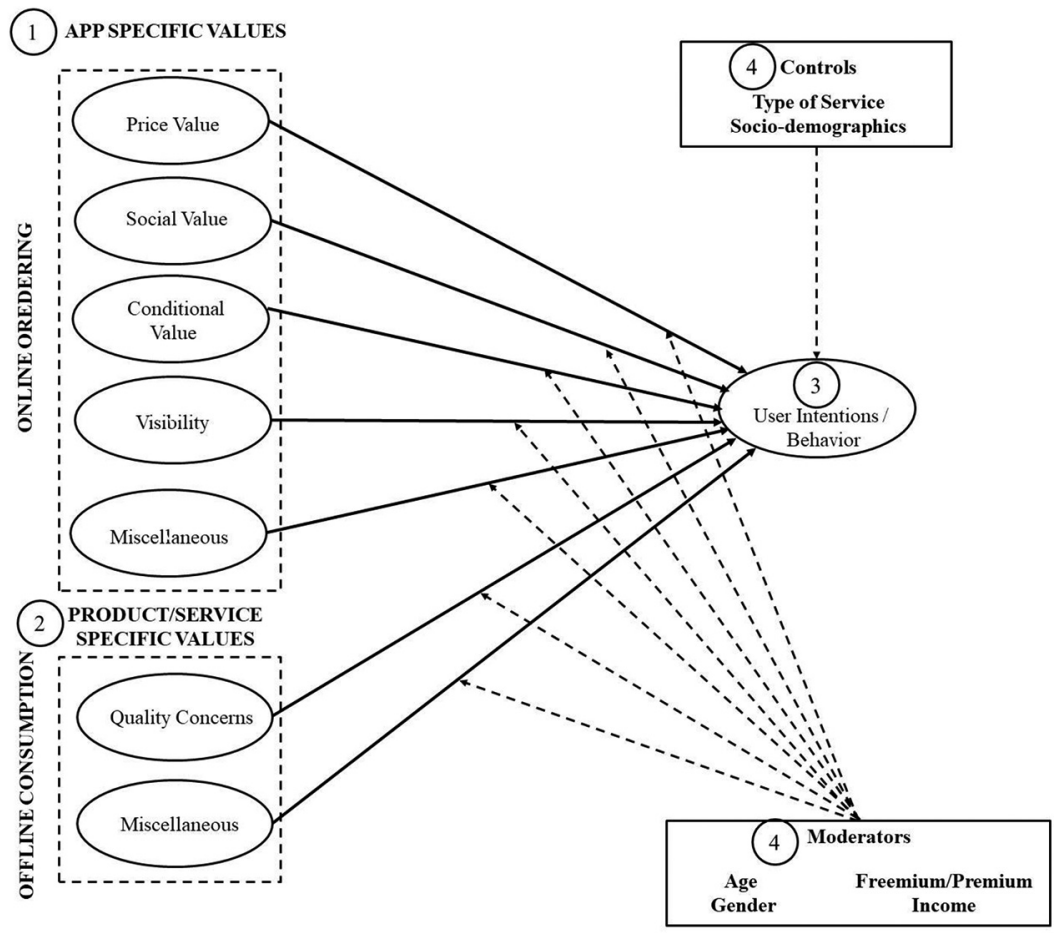

Proposition of food delivery apps

further qualitative studies are necessary to identify values specific to the contexts of particular $\mathrm{O} 2 \mathrm{O}$ services.

- Dependent variables: A salient feature of this model is that it considers both user intentions and actual use behavior as outcome variables because perceived values derived from $\mathrm{O} 2 \mathrm{O}$ services may transcend influencing user intentions positively or negatively and influence actual buying behavior.

- Controls and moderators: We recommend that future researchers also consider control and moderating variables along with the antecedents and consequents discussed above. Socio-demographic factors have moderating effects on the strength of associations in consumer behavior models. Additionally, since this model targets $\mathrm{O} 2 \mathrm{O}$ services, we encourage future researchers to consider freemium/premium subscriptions as sources of individual differences among users. Intuitively, the association of values with intentions toward $\mathrm{O} 2 \mathrm{O}$ may vary with the type of service or product booked (e.g., budget or luxury hotels, leisure or business travel, adventure, health tourism, etc.). Hence, we recommend the use of variables that resemble moderating or control variables.

Second, this study responds to the call for more research on OFDs and FDAs (Correa et al., 2019). An examination of the extant literature shows that studies on FDAs have largely focused on acceptance from a technology perspective, leaving other aspects of consumer behavior under-explored (Alalwan, 2020; Lee et al., 2019b). Notably, despite the successful use of the TCV in the context of hospitality and tourism (Talwar et al., 2020a; 
IJCHM

33,4

Rodrigo and Turnbull, 2019), no empirical study has identified or examined the consumption values associated with the use of FDAs. Consistent with researchers such as Perrea et al. (2015), by adapting the pivotal propositions of the TCV to the FDA context, the present study paves the way for future researchers to extend the generic TCV values to various $\mathrm{O} 2 \mathrm{O}$ services in the hospitality domain, such as online travel agencies (OTAs), cab sharing, and so on.

Third, the present study identifies health consciousness and food safety concerns as possibly negative consumption values that may reduce intentions to order food via FDAs. These two factors are key influencers of food choices (Dubé et al., 2016). The inclusion of these variables in the context of FDAs is timely and important for two reasons:

(1) The spread of COVID-19 and its highly contagious nature has caused many to take extreme precautions related to health and food. The revenues of FDAs may fall dramatically if they do not align their strategies with a renewed focus on health and food safety. In this context, inputs from academic research may prove valuable.

(2) Recent studies have highlighted the role of OFD platforms in the transmission of foodborne diseases (Jiang et al., 2020), so the present study makes a key theoretical contribution by focusing the academic community on these two concerns in connection with FDAs.

Fourth, from a conceptual perspective, this study's exploratory mixed-method approach to extend an existing theory to a new-economy business model (i.e. O2O) supports the use of the FGD method for adapting existing measures to new contexts (Krueger and Casey, 2009). This may aid future researchers in adapting seminal theories to the contexts of other digitally driven products and services, particularly in the hospitality sector.

Finally, this research provides information about the consumption values of Indian FDA users by investigating their choice behavior while ordering food for delivery. It is important for researchers to understand the behavior of Indian FDA users, as they represent a large segment of FDA customers worldwide. In fact, there are 1 million food deliveries daily in India (Jindal, 2018). This study's contribution becomes even more important in this context because prior studies have noted geographical disparities in consumer behavior toward FDAs (Lee, 2019), underscoring the need for studies that focus on different geographies and culture. This also makes practical sense because FDAs operating in any area must strategize according to local considerations, so research insights from geographically focused studies could be useful for them.

\subsection{Practical implications}

Service providers and marketers interested in strengthening intentions to order food from FDAs can benefit by manipulating the values this study has identified as significant. First, given that visibility ( $\beta=0.43$ ) is the chief driver of purchase intentions, FDAs can increase their customer base through advertising that focuses on existing users. Other channels, such as word of mouth, referrals, and endorsements, can also be effective. In fact, word of mouth is fast becoming a key tool of brand recommendation among consumers (Liu and Lopez, 2016), especially via social media (Mahapatra and Mishra, 2017).

Second, this study has shown that affordances value, measured in terms of free and fast delivery, improves purchase intentions toward FDAs. FDAs should therefore work on ways to accelerate food delivery and control delivery-related costs. For instance, food delivery through drones, which has been tested in Korea (Hwang et al, 2019a), can help FDAs evade traffic congestion. Although the cost of acquiring drones may prove challenging, the long-term benefits, including the diminished need for delivery personnel, are likely to offset their high cost. 
Third, price and prestige values have been identified as positive drivers of intentions to order food via FDAs, which implies that competitive prices and discounts should be offered to consumers. As offering discounts on food orders has its own limitations, other strategies may employed, such as limited free subscriptions, free meals after a certain number of deliveries, or freebies through tie-ups with other firms. Furthermore, since users seem to attach prestige value to the use of these apps, FDAs can use strategies such as recognizing the most frequent user in a particular area within a fixed period on their Facebook page or Twitter handle.

Proposition of food delivery apps

1151

\subsection{Research limitations and future research areas}

Despite its notable contributions, this study has some limitations that must be acknowledged. First, it focuses only on FDAs in the Indian market, so the findings may not be applicable to FDAs in other cultural contexts or to other mobile apps for booking or buying products and services. This limited generalizability can be addressed by future researchers trying to validate the findings of this study in other cultural backgrounds, geographies, and with other FDA service providers. Second, the study uses a cross-sectional design, so relies on self-reported data collected at one point in time, which introduces the possibility of biased findings. Scholars can use other research designs, such as longitudinal and experimental ones, to overcome this limitation and add credibility to future research findings. Third, we collected the data before the COVID-19 pandemic lockdown in India (The Lancet, 2020). Therefore, the findings are relevant under normal circumstances and do not represent outlier behavior during the coronavirus crisis. According to media reports, FDA deliveries are still taking place in India during the extended lockdown (Nandy and Mathur, 2020), and the findings of our study should be valid in the post-lockdown period. This is in consonance with experience of Delivery Hero SE, the Berlin-based food-delivery firm that has witnessed a rise in orders for delivery during lockdown and anticipates longterm benefits as more customers are willing to opt for food delivery from restaurants (Syed, 2020). We suggest that future researchers test our model by collecting data based on the lockdown experiences of FDA users and map the distinctions. Such studies would help capture the drivers of consumption values more commensurate with the enhanced food safety concerns and health consciousness that can be expected due to the highly contagious nature of the COVID-19 virus. Such findings would be of great value to FDA service providers in particular and OFDs in general, as changed health behaviors due to COVID-19 may continue to be a way of life in the foreseeable future. It is also important to note that we have used age and gender as moderators, ignoring the possibility of using them as control variables or even mediators. Future studies can add new dimensions to our findings by considering these two demographic variables as controls or mediators. It would also be interesting to explore the moderating role of variables such as moral obligations in meal preparation, as suggested by Roh and Park (2019), moderating effect of technology anxiety in the context of mobile app use, as examined by Kang and Namkung (2019b) and freemium/ premium subscriptions, as discussed by Mäntymäki et al. (2019) for online digital content. We also recommend further empirical testing of the proposed $\mathrm{O} 2 \mathrm{O} \mathrm{TCV}$ model to measure consumption values related to other $\mathrm{O} 2 \mathrm{O}$ services in the hospitality sector. Furthermore, future research can expand our model to include the following aspects:

- service dimension, since service is inseparable part of hospitality experience (Kandampully et al., 2018);

- affective evaluations and customer satisfaction, which are important from hospitality perspective (Lee et al., 2019a); 
IJCHM

33,4

1152

- performance expectancy which is a significant driver of the intentions to use online food delivery systems (OFDS) (Gunden et al., 2020);

- electronic word of mouth (eWOM) intentions, as scholars have noted the growing importance of the effect of viral eWOM on brands (Moro and Rita, 2018); and

- effect of new technologies such as augmented reality and artificial intelligence on FDA use experience, since these technologies are transforming the hospitality and tourism sector (Law et al., 2019).

It would also be interesting to investigate consumption values among non-FDA users. This would improve our understanding of the differences between users and non-users and be immensely useful to FDA service providers. Future studies should also conduct rigorous qualitative studies to enhance our understanding of how and why people use FDAs. Future studies investigating the behavioral intentions of specific demographic groups toward ordering food on FDAs, such as housewives, students, and so on, would also provide valuable insights for FDA service providers. Finally, scholars should use other relevant theories to understand the behavioral intentions of consumers, such as behavioral reasoning theory (Westaby, 2005).

\section{References}

Alagoz, S.M. and Hekimoglu, H. (2012), "A study on tam: analysis of customer attitudes in online food ordering system”, Procedia - Social and Behavioral Sciences, Vol. 62, pp. 1138-1143.

Alalwan, A.A. (2020), "Mobile food ordering apps: an empirical study of the factors affecting customer e-satisfaction and continued intention to reuse", International Journal of Information Management, Vol. 50, available at: https://doi.org/10.1016/j.ijinfomgt.2019.04.008

Alavi, S.A., Rezaei, S., Valaei, N. and Wan Ismail, W.K. (2016), "Examining shopping mall consumer decisionmaking styles, satisfaction and purchase intention", International Review of Retail, Distribution and Consumer Research, available at: https://oi.org/10.1080/09593969.2015.1096808

Anderson, J.C. and Gerbing, D.W. (1988), "Structural equation modeling in practice: a review and recommended two-step approach", Psychological Bulletin, Vol. 103 No. 3, Available at: https://doi. org/10.1037/0033-2909.103.3.411

Ashton, A.S. (2015), "Developing a tourist destination Brand value: the stakeholders' perspective", Tourism Planning and Development, available at: https://doi.org/10.1080/21568316.2015.1013565

Belanche, D., Flavián, M. and Pérez-Rueda, A. (2020), "Mobile apps use and WOM in the food delivery sector: the role of planned behavior, perceived security and customer lifestyle compatibility", Sustainability, Vol. 12 No. 10, doi: 10.3390/su12104275.

Bernini, C. and Cracolici, M.F. (2015), "Demographic change, tourism expenditure and life cycle behaviour", Tourism Management, Vol. 47, pp. 191-205, available at: https://doi.org/10.1016/j. tourman.2014.09.016

Bødker, M., Gimpel, G. and Hedman, J. (2009), "The user experience of smartphones: a consumption values approach", Proceedings of the Global Mobility Roundtable Conference, Cairo, 1-3 November.

Buhrau, D. and Ozturk, T.C. (2018), "Motivating healthy eating: the role of presentation format and health consciousness", Food Quality and Preference, Vol. 64, pp. 167-171, doi: 10.1016/j. foodqual.2017.09.011.

Casaló, L.V., Flavián, C., Guinalíu, M. and Ekinci, Y. (2015), "Do online hotel rating schemes influence booking behaviors? ”, International Journal of Hospitality Management, Vol. 49, available at: https://doi.org/10.1016/j.ijhm.2015.05.005 
Chang, R.C.Y., Kivela, J. and Mak, A.H.N. (2010), "Food preferences of chinese tourists", Annals of Tourism Research, Vol. 37 No. 4, available at: https://doi.org/10.1016/j.annals.2010.03.007

Cho, M., Bonn, M.A. and Li, J. (2019), "Differences in perceptions about food delivery apps between single-person and multi-person households", International Journal of Hospitality Management, Vol. 77, available at: https://doi.org/10.1016/j.ijhm.2018.06.019

Choe, J.Y. and Kim, S. (2018), "Effects of tourists' local food consumption value on attitude, food destination image, and behavioral intention", International Journal of Hospitality Management, Vol. 71, available at: https://doi.org/10.1016/j.ijhm.2017.11.007

Choe, J.Y. and Kim, S. (2019), "Development and validation of a multidimensional tourist's local food consumption value (TLFCV) scale", International Journal of Hospitality Management, Vol. 77, available at: https://doi.org/10.1016/j.jhm.2018.07.004

Clark, J., Crandall, P. and Reynolds, J. (2019), "Exploring the influence of food safety climate indicators on handwashing practices of restaurant food handlers", International Journal of Hospitality Management, Vol. 77, pp. 187-194, doi: 10.1016/j.ijhm.2018.06.029.

Correa, J.C., Garzón, W., Brooker, P., Sakarkar, G., Carranzaa, S.A., Yunado, L. and Rincón, A. (2019), "Evaluation of collaborative consumption of food delivery services through web mining techniques", Journal of Retailing and Consumer Services, Vol. 46, doi: 10.1016/j.jretconser.2018.05.002.

Dhir, A., Khalil, A., Lonka, K. and Tsai, C.C. (2017), "Do educational affordances and gratifications drive intensive facebook use among adolescents? ”, Computers in Human Behavior, Vol. 68, available at: https://doi.org/10.1016/j.chb.2016.11.014

Di Talia, E., Simeone, M. and Scarpato, D. (2019), “Consumer behaviour types in household food waste”, Journal of Cleaner Production, Vol. 214, pp. 166-172, available at: https://doi.org/10.1016/j.jclepro.2018.12.216

Dodds, W.B., Monroe, K.B. and Grewal, D. (1991), "Effects of price, Brand, and store information on buyers' product evaluations", Journal of Marketing Research, Vol. 28 No. 3, pp. 307-e319.

Dua, A. (2017), "Challenges that online food delivery restaurants and services face", available at: https:// yourstory.com/2017/10/challenges-that-online-food-delivery-restaurants-and-services-face

Dubé, L., Fatemi, H., Lu, J. and Hertzer, C. (2016), "The healthier the tastier? USA-India comparison studies on consumer perception of a nutritious agricultural product at different food processing levels", Frontiers in Public Health, Vol. 4, available at: https://doi.org/10.3389/fpubh.2016.00006

Elliot, S., Papadopoulos, N. and Kim, S.S. (2011), "An integrative model of place image: exploring relationships between destination, product, and country images", Journal of Travel Research, Vol. 50 No. 5, Available at: https://doi.org/10.1177/0047287510379161

Fornell, C. and Larcker, D.F. (1981), "Evaluating structural equation models with unobservable variables and measurement error", Journal of Chemical Information and Modeling, Available at: https://doi.org/10.1017/CBO9781107415324.004

Glaser, B.G. and Strauss, A. (1967), The Discovery Grounded Theory: strategies for Qualitative Inquiry, Aldin, Chicago.

Gómez, M., Imhoff, B., Martín-Consuegra, D., Molina, A. and Santos-Vijande, M.L. (2018), "Language tourism: the drivers that determine destination choice intention among U.S. students", Tourism Management Perspectives, Vol. 27Available at: https://doi.org/10.1016/j.tmp.2018.06.001

Gonçalves, H.M., Lourenço, T.F. and Silva, G.M. (2016), "Green buying behavior and the theory of consumption values: a fuzzy-set approach”, Journal of Business Research, Vol. 69 No. 4, available at: https://doi.org/10.1016/j.jbusres.2015.10.129

Gunden, N., Morosan, C. and DeFranco, A. (2020), "Consumers' intentions to use online food delivery systems in the USA", International Journal of Contemporary Hospitality Management, Vol. 32 No. 3, pp. 1325-1345, doi: 10.1108/ijchm-06-2019-0595.

Guo, Y., Zhu, Y., Barnes, S.J., Bao, Y., Li, X. and Le-Nguyen, K. (2018), "Understanding cross-product purchase intention in an IT Brand extension context", Psychology and Marketing, available at: https://doi.org/10.1002/mar.21094
Proposition of food delivery apps 
IJCHM 33,4
Hair, J.F., Black, W.C., Babin, B.J. and Anderson, R.E. (2016), Multivariate Data Analysis, 7th Edition. Pearson: New Delhi.

Harman, H.H. (1976), Modern Factor Analysis, 3rd Edition, The University of Chicago Press, Chicago.

Harris, K.J., DiPietro, R.B., Murphy, K.S. and Rivera, G. (2014), "Critical food safety violations in Florida: relationship to location and chain vs. non-chain restaurants", International Journal of Hospitality Management, Vol. 38, pp. 57-64, doi: 10.1016/j.ijhm.2013.12.005.

He, Z., Han, G., Cheng, T.C.E., Fan, B. and Dong, J. (2019), "Evolutionary food quality and location strategies for restaurants in competitive online-to-offline food ordering and delivery markets: an agent-based approach", International Journal of Production Economics, Vol. 215, available at: https://doi.org/10.1016/j.ijpe.2018.05.008

Her, E. and Seo, S. (2017), "Health halo effects in sequential food consumption: the moderating roles of health-consciousness and attribute framing", International Journal of Hospitality Management, Vol. 62, pp. 1-10, doi: 10.1016/j.ijhm.2016.11.009.

Hew, T.S. and Kadir, S.L.S.A. (2016), "Predicting instructional effectiveness of cloudbased virtual learning environment”, Industrial Management and Data Systems, Vol. 116 No. 8, pp. 1557-1584. Available at: https://doi.org/10.1108/IMDS-11-2015-0475.

Hew, J.-J., Leong, L.-Y., Tan, G.W.-H., Ooi, K.-B. and Lee, V.-H. (2019), "The age of mobile social commerce: an artificial neural network analysis on its resistances", Technological Forecasting and Social Change, Vol. 144, pp. 311-324, doi: 10.1016/j.techfore.2017.10.007.

Hirschberg, C. Rajko, A. Schumacher, T. and Wrulich, M. (2016), "The changing market for food delivery", Mckinsey.Com, available at: https://doi.org/10.1016/j.jembe.2008.12.003

Ho, S.Y. and Bodoff, D. (2014), "The effects of web personalization on user attitude and behavior: an integration of the elaboration likelihood model and consumer search theory", MIS Quarterly, Vol. 38 No. 2, pp. 497-520.

Holbrook, M.B. (1996), "Customer value - a framework for analysis and research", Advances in Consumer Research, Vol. 23 No. 1, pp. 138-142.

Hur, W.M., Yoo, J.J. and Chung, T.L. (2012), "The consumption values and consumer innovativeness on convergence products", Industrial Management and Data Systems, available at: https://doi.org/10.1108/ 02635571211232271

Hussain, M. and Dawson, C. (2013), "Economic impact of food safety outbreaks on food businesses", Foods, Vol. 2 No. 4, Foods. available at: https://doi.org/10.3390/foods2040585

Hwang, J., Kim, H. and Kim, W. (2019a), "Investigating motivated consumer innovativeness in the context of drone food delivery services", Journal of Hospitality and Tourism Management, Vol. 38, available at: https://doi.org/10.1016/j.jhtm.2019.01.004

Hwang, J., Lee, J.S. and Kim, H. (2019b), "Perceived innovativeness of drone food delivery services and its impacts on attitude and behavioral intentions: the moderating role of gender and age", International Journal of Hospitality Management, Vol. 81, pp. 94-103, doi: 10.1016/j.ijhm.2019.03.002.

Jamrozy, U. and Lawonk, K. (2017), "The multiple dimensions of consumption values in ecotourism”, International Journal of Culture, Tourism and Hospitality Research, Vol. 11 No. 1, available at: https://doi.org/10.1108/IJCTHR-09-2015-0114

Jiang, M., Zhu, F., Yang, C., Deng, Y., Kwan, P.S.L., Li, Y., ... Hu, Q. (2020), "Whole-genome analysis of salmonella enterica serovar enteritidis isolates in outbreak linked to online food delivery, shenzhen, China, 2018”, Emerging Infectious Diseases, Vol. 26 No. 4, pp. 789-792, doi: 10.3201/eid2604.191446.

Jindal, V. (2018), "Why india's next unicorn could come from the food tech services industry", available at: https://yourstory.com/2018/09/india-food-tech-services-industry-prospects

Johnson, V.L., Kiser, A., Washington, R. and Torres, R. (2018), "Limitations to the rapid adoption of mpayment services: understanding the impact of privacy risk on m-payment services", Computers in Human Behavior, Vol. 79, available at: https://doi.org/10.1016/j.chb.2017.10.035 
Kandampully, J., Zhang, T. and Jaakkola, E. (2018), “Customer experience management in hospitality: a literature synthesis, new understanding and research agenda", International Journal of Contemporary Hospitality Management, Vol. 30 No. 1, pp. 21-56, available at: https://doi.org/10.1108/IJCHM-10-2015-0549

Kang, J.-W. and Namkung, Y. (2019a), "The information quality and source credibility matter in customers' evaluation toward food $\mathrm{O} 2 \mathrm{O}$ commerce", International Journal of Hospitality Management, Vol. 78, pp. 189-198, doi: 10.1016/j.ijhm.2018.10.011.

Kang, J.-W. and Namkung, Y. (2019b), "The role of personalization on continuance intention in food service mobile apps", International Journal of Contemporary Hospitality Management, Vol. 31 No. 2, pp. 734-752, doi: 10.1108/ijchm-12-2017-0783.

Kapoor, A.P. and Vij, M. (2018), "Technology at the dinner table: Ordering food online through mobile apps", Journal of Retailing and Consumer Services, Vol. 43, pp. 342-351, doi: 10.1016/j.jretconser.2018.04.001.

Kaur, P., Dhir, A., Rajala, R. and Dwivedi, Y. (2018), "Why people use online social media Brand communities:a consumption value theory perspective", Online Information Review, Vol. 42 No. 2 , Available at: https://doi.org/10.1108/OIR-12-2015-0383

Kaur, P., Dhir, A., Ray, A., Bala, P. and Khalil, A. (2020), "Innovation resistance theory perspective on the use of food delivery applications", Journal of Enterprise Information Management,

Kim, Y.G. and Eves, A. (2012), "Construction and validation of a scale to measure tourist motivation to consume local food”, Tourism Management, Vol. 33 No. 6, available at: https:/doi.org/10.1016/j.tourman.2012.01.015

Kim, J.J. and Lee, A.J. (2017), "A study on the effect of consumption value with planned behavior theory on purchase intention of the consumers of the michelin-starred restaurant in Seoul", FoodService Industry Journal, Available at: https://doi.org/10.22509/kfsa.2017.13.3.012

Kim, S., Choe, J.Y. and Lee, S. (2018b), "How are food value video clips effective in promoting food tourism? Generation Y versus non-generation Y", Journal of Travel and Tourism Marketing, available at: https://doi.org/10.1080/10548408.2017.1320262

Kim, E., Tang, L.R. and Bosselman, R. (2018a), "Measuring customer perceptions of restaurant innovativeness: Developing and validating a scale", International Journal of Hospitality Management, Vol. 74, available at:https://doi.org/10.1016/j.ijhm.2018.02.018

Kock, N. and Lynn, G. (2012), "Lateral collinearity and misleading results in variance-based SEM: an illustration and recommendations", Journal of the Association for Information Systems, Vol. 13 No. 7, pp. 546-580, doi: 10.17705/1jais.00302.

Krueger, R.A. and Casey, M.A. (2009), A Practical Guide for Applied Research, Sage Publications, New York, NY. Available at: https://doi.org/10.1002/j.1556-6678.2007.tb00462.x

Kushwah, S., Dhir, A. and Sagar, M. (2019), "Ethical consumption intentions and choice behavior towards organic food. Moderation role of buying and environmental concerns", Journal of Cleaner Production, Vol. 236, doi: 10.1016/j.jclepro.2019.06.350.

Law, R., Leung, D. and Chan, I.C.C. (2019), "Progression and development of information and communication technology research in hospitality and tourism", International Journal of Contemporary Hospitality Management, Vol. 32 No. 2, pp. 511-534, doi: 10.1108/ijchm-07-2018-0586.

Lee, J.-H. (2019), "Effects of service and mobile app quality on customer satisfaction and repurchase intention in the context of $\mathrm{O} 2 \mathrm{O}$ food delivery services in Korea and China", Test Engineering and Management, Vol. 81 No. 11-12, pp. 335-345.

Lee, E.-Y., Lee, S.-B. and Jeon, Y.J.J. (2017), "Factors influencing the behavioral intention to use food delivery apps", Social Behavior and Personality: An International Journal, Vol. 45 No. 9, pp. 1461-1473, doi: 10.2224/sbp.6185.

Lee, M., Lee, S. and Koh, Y. (2019a), "Multisensory experience for enhancing hotel guest experience: Empirical evidence from big data analytics", International Joumal of Contemporary Hospitality Management, Vol. 31 No. 11, pp. 4313-4337, available at: https://doi.org/10.1108/IJCHM-03-2018-0263

Lee, S.W., Sung, H.J. and Jeon, H.M. (2019b), "Determinants of continuous intention on food delivery apps: extending UTAUT2 with information quality", Sustainability, Vol. 11 No. 11, doi: 10.3390/su11113141. 
$\mathrm{IJCHM}$ 33,4

Lee, K., Conklin, M., Bordi, P. and Cranage, D. (2016), "Restaurants' healthy eating initiatives for children increase parents' perceptions of CSR, empowerment, and visit intentions", International Journal of Hospitality Management, Vol. 59, pp. 60-71, doi: 10.1016/j.jhm.2016.07.008.

Lee, K., Conklin, M., Cranage, D.A. and Lee, S. (2014), "The role of perceived corporate social responsibility on providing healthful foods and nutrition information with health-consciousness as a moderator", International Journal of Hospitality Management, Vol. 37, available at: https:// doi.org/10.1016/j.ijhm.2013.10.005

Leong, L.-Y., Hew, T.-S., Ooi, K.-B. and Wei, J. (2020), "Predicting mobile wallet resistance: a two-staged structural equation modeling-artificial neural network approach", International Journal of Information Management, Vol. 51, doi: 10.1016/j.ijinfomgt.2019.102047.

Lin, P.C. and Huang, Y.H. (2012), "The influence factors on choice behavior regarding green products based on the theory of consumption values", Journal of Cleaner Production, Vol. 22 No. 1, Available at: https://doi.org/10.1016/j.jclepro.2011.10.002

Litvin, S.W., Goldsmith, R.E. and Pan, B. (2018), "A retrospective view of electronic word-of-mouth in hospitality and tourism management", International Journal of Contemporary Hospitality Management, Vol. 30 No. 1, pp. 313-325, doi: 10.1108/ijchm-08-2016-0461.

Liu, P. and Lee, Y.M. (2018), "An investigation of consumers' perception of food safety in the restaurants", International Journal of Hospitality Management, Vol. 73, pp. 29-35, doi: 10.1016/j.ijhm.2018.01.018.

Liu, Y. and Lopez, R.A. (2016), "The impact of social media conversations on consumer Brand choices", Marketing Letters, Vol. 27 No. 1, Available at: https://doi.org/10.1007/s11002-014-9321-2

Liu, P. and Ma, L. (2016), "Food scandals, media exposure, and citizens' safety concerns: a multilevel analysis across chinese cities", Food Policy, Vol. 63, available at: https://doi.org/10.1016/j. foodpol.2016.07.005

Long, M.M. and Schiffman, L.G. (2000), "Consumption values and relationships: segmenting the market for frequency programs", Journal of Consumer Marketing, Vol. 17 No. 3, pp. 214-232, doi: $10.1108 / 07363760010329201$.

Maberry, T. (2016), “A look back at 2015 food recalls”, Food Safety Magazine.

Mahapatra, S. and Mishra, A. (2017), "Acceptance and forwarding of electronic word of mouth", Marketing Intelligence and Planning, Vol. 35 No. 5, available at: https://oi.org/10.1108/MIP-01-2017-0007

Mak, A.H.N., Lumbers, M., Eves, A. and Chang, R.C.Y. (2012), "Factors influencing tourist food consumption", International Journal of Hospitality Management, Vol. 31 No. 3, available at: https://doi.org/10.1016/j.ijhm.2011.10.012

Mäntymäki, M. and Salo, J. (2015), "Why do teens spend real money in virtual worlds? A consumption values and developmental psychology perspective on virtual consumption", International Journal of Information Management, Vol. 35 No. 1, pp. 124-134, doi: 10.1016/j.jinfomgt.2014.10.004.

Mäntymäki, M., Najmul Islam, A.K.M. and Benbasat, I. (2019), "What drives subscribing to premium in freemium services? A consumer value-based view of differences between upgrading to and staying with premium", Information Systems Journal, Vol. 30 No. 2, pp. 295-333, doi: 10.1111/ isj.12262.

Meyers-Levy, J. and Loken, B. (2015), "Revisiting gender differences: what we know and what lies ahead”, Journal of Consumer Psychology, Vol. 25 No. 1, pp. 129-149.

Moro, S. and Rita, P. (2018), "Brand strategies in social media in hospitality and tourism", International Journal of Contemporary Hospitality Management, Vol. 30 No. 1, pp. 343-364, doi: 10.1108/ijchm-07-2016-0340.

Morosan, C. and Bowen, J.T. (2018), "Analytic perspectives on online purchasing in hotels: a review of literature and research directions", International Journal of Contemporary Hospitality Management, Vol. 30 No. 1, pp. 557-580, doi: 10.1108/ijchm-10-2016-0566.

Morosan, C. and DeFranco, A. (2016), "Co-creating value in hotels using mobile devices: a conceptual model with empirical validation", International Journal of Hospitality Management, Vol. 52Available at: https://doi.org/10.1016/j.ijhm.2015.10.004 
Morosan, C. and DeFranco, A. (2019), "Co-creation of value using hotel interactive technologies: examining intentions and conversion", International Journal of Contemporary Hospitality Management, Vol. 31 No. 3, pp. 1183-1204, doi: 10.1108/ijchm-04-2018-0314.

Mun, S.G. (2020), "The effects of ambient temperature changes on foodborne illness outbreaks associated with the restaurant industry", International Journal of Hospitality Management, Vol. 85, doi: 10.1016/j.ijhm.2019.102432.

Najmul Islam, A.K.M., Mäntymäki, M. and Bhattacherjee, A. (2017), "Towards a decomposed expectation confirmation model of it continuance: the role of usability", Communications of the Association for Information Systems, Vol. 40, pp. 502-523, doi: 10.17705/1cais.04023.

Nandy, M. and Mathur, N. (2020), "E-tailers, food delivery firms brace for extended lockdown regime", Available at: www.livemint.com/industry/retail/e-tailers-food-delivery-firms-brace-for-extendedlockdown-regime-11586929960679.html

Nayak, R. and Waterson, P. (2017), "The assessment of food safety culture: an investigation of current challenges, barriers and future opportunities within the food industry", Food Control, Vol. 73, available at: https://doi.org/10.1016/j.foodcont.2016.10.061

Nejati, M. and Moghaddam, P.P. (2013), "The effect of hedonic and utilitarian values on satisfaction and behavioural intentions for dining in fast-casual restaurants in Iran”, British Food Journal, Vol. 115 No. 11, available at: https://doi.org/10.1108/BFJ-10-2011-0257

Okumus, B., Ali, F., Bilgihan, A. and Ozturk, A.B. (2018), "Psychological factors influencing customers' acceptance of smartphone diet apps when ordering food at restaurants", International Journal of Hospitality Management, Vol. 72, pp. 67-77.

Okumus, B., Sönmez, S., Moore, S., Auvil, D.P. and Parks, G.D. (2019), "Exploring safety of food truck products in a developed country", International Journal of Hospitality Management, Vol. 81, pp. 150-158, doi: 10.1016/j.ijhm.2019.02.011.

Peng, N., Chen, A. and Hung, K.-P. (2019), "Dining at luxury restaurants when traveling abroad: incorporating destination attitude into a luxury consumption value model", Journal of Travel and Tourism Marketing, Vol. 1, doi: 10.1080/10548408.2019.1568352.

Perrea, T., Grunert, K.G. and Krystallis, A. (2015), "Consumer value perceptions of food products from emerging processing technologies: a cross-cultural exploration”, Food Quality and Preference, Vol. 39, available at: https://doi.org/10.1016/j.foodqual.2014.06.009

Phau, I., Quintal, V. and Shanka, T. (2014), "Examining a consumption values theory approach of young tourists toward destination choice intentions", International Journal of Culture, Tourism, and Hospitality Research, available at: https://doi.org/10.1108/IJCTHR-12-2012-0090

Podsakoff, P.M., MacKenzie, S.B. and Podsakoff, N.P. (2012), "Sources of method bias in social science research and recommendations on how to control it", Annual Review of Psychology, Vol. 63 No. 1, pp. 539-569, available at: https://doi.org/10.1146/annurev-psych-120710-100452

Polites, G. and Karahanna, E. (2012), "Shackled to the status quo: the inhibiting effects of incumbent system habit, switching costs, and inertia on new system acceptance", MIS Quarterly, Vol. 36 No. 1, pp. 21, doi: $10.2307 / 41410404$.

Prabowo, G.T. and Nugroho, A. (2019), "Factors that influence the attitude and behavioral intention of Indonesian users toward online food delivery service by the Go-Food application", Proceedings of the 12th International Conference on Business and Management Research (ICBMR 2018). 10.2991/icbmr-18.2019.34

Ray, A., Dhir, A., Bala, P.K. and Kaur, P. (2019), "Why do people use food delivery apps (FDA)? a uses and gratification theory perspective", Journal of Retailing and Consumer Services, Vol. 51, pp. 221-230, doi: 10.1016/j.jretconser.2019.05.025.

Rodrigo, P. and Turnbull, S. (2019), "Halal holidays: How is value perceived by muslim tourists?", International Journal of Tourism Research, Vol. 21 No. 5, pp. 675-692, doi: 10.1002/jtr.2290. 
$\mathrm{IJCHM}$ 33,4

Roh, M. and Park, K. (2019), “Adoption of O2O food delivery services in South Korea: the moderating role of moral obligation in meal preparation”, International Journal of Information Management, Vol. 47, available at: https://doi.org/10.1016/j.ijinfomgt.2018.09.017

Rousta, A. and Jamshidi, D. (2019), "Food tourism value: Investigating the factors that influence tourists to revisit", Journal of Vacation Marketing, Vol. 26 No. 1, pp. 73-95, doi: 10.1177/1356766719858649.

Saarijärvi, H., Mitronen, L. and Yrjölä, M. (2014), "From selling to supporting - Leveraging mobile services in the context of food retailing", Journal of Retailing and Consumer Services, Vol. 21 No. 1, available at: https://doi.org/10.1016/j.jretconser.2013.06.009

Sheth, J.N., Newman, B.I. and Gross, B.L. (1991), "Why we buy what we buy: a theory of consumption values", Journal of Business Research, Vol. 22 No. 2, available at: https://doi.org/10.1016/0148-2963(91)90050-8

Shin, J. and Mattila, A.S. (2019), "When organic food choices shape subsequent food choices: the interplay of gender and health consciousness", International Journal of Hospitality Management, Vol. 76, pp. 94-101, doi: 10.1016/j.ijhm.2018.04.008.

Shin, Y.H., Im, J., Jung, S.E. and Severt, K. (2018), "The theory of planned behavior and the norm activation model approach to consumer behavior regarding organic menus", International Journal of Hospitality Management, Vol. 69, available at: https://doi.org/10.1016/j.ijhm.2017.10.011

Sinha, I. and DeSarbo, W.S. (2006), "An integrated approach toward the spatial modeling of perceived customer value”, Journal of Marketing Research, Vol. 35 No. 2, available at: https://doi.org/10.2307/3151851

2019). "Platform-to-Consumer delivery", available at: www.statista.com/outlook/376/100/platform-toconsumer-delivery/worldwideStatista.

Statista (2020), "Platform-to-Consumer delivery", available at: www.statista.com/outlook/376/119/ platform-to-consumer-delivery/india

Suhartanto, D., Helmi Ali, M., Tan, K.H., Sjahroeddin, F. and Kusdibyo, L. (2019), "Loyalty toward online food delivery service: the role of e-service quality and food quality", Journal of Foodservice Business Research, Vol. 22 No. 1, pp. 81-97.

Sweeney, J.C. and Soutar, G.N. (2001), "Consumer perceived value: the development of a multiple item scale", Journal of Retailing, Vol. 77 No. 2, available at: https://doi.org/10.1016/S0022-4359(01)00041-0

Syed, S. (2020), "Delivery hero food orders almost double during lockdown", available at: www. bloombergquint.com/onweb/delivery-hero-orders-jump-92-as-lockdown-boosts-food-delivery

Talwar, S., Dhir, A., Kaur, P. and Mäntymäki, M. (2020a), "Why do people purchase from online travel agencies (OTAs)? A consumption values perspective", International Journal of Hospitality Management, Vol. 88, doi: 10.1016/j.jhm.2020.102534.

Talwar, S., Dhir, A., Kaur, P. and Mäntymäki, M. (2020b), "Barriers toward purchasing from online travel agencies", International Journal of Hospitality Management, Vol. 89, p. 102593, doi: 10.1016/j.ijhm.2020.102593.

Talwar, S., Dhir, A., Singh, D., Virk, G.S. and Salo, J. (2020c), "Sharing of fake news on social media: Application of the honeycomb framework and the third-person effect hypothesis", Journal of Retailing and Consumer Services, Vol. 57, doi: 10.1016/j.jretconser.2020.102197.

Tan, G.W.-H. and Ooi, K.-B. (2018), "Gender and age: Do they really moderate mobile tourism shopping behavior", ? Telematics and Informatics, Vol. 35 No. 6, pp. 1617-1642, doi: 10.1016/j. tele.2018.04.009.

Tandon, S. (2018), "India's food delivery firms are under fire for ignoring safety and hygiene", available at: https:/qz.com/india/1346827/zomato-swiggy-and-the-rest-can-no-longer-ignore-the-quality-of-food-theydeliver/

The Lancet (2020), "India under COVID-19 lockdown”, The Lancet, Vol. 395 No. 10233, doi: 10.1016/ s0140-6736(20)30938-7.

Thomé, K.M., Pinho, G.M. and Hoppe, A. (2019), "Consumption values and physical activities: consumers' healthy eating choices", British Food Journal, Vol. 121 No. 2, available at: https://doi. org/10.1108/BFJ-12-2017-0683 
Wasserstrom (2018), "The 5 biggest food delivery risks", available at: www.wasserstrom.com/blog/ 2018/10/12/food-delivery-risks/

Westaby, J.D. (2005), "Behavioral reasoning theory: identifying new linkages underlying intentions and behavior", Organizational Behavior and Human Decision Processes, Vol. 98 No. 2, available at: https://doi.org/10.1016/j.obhdp.2005.07.003

Williams, P. and Soutar, G.N. (2009), "Value, satisfaction and behavioral intentions in an adventure tourism context", Annals of Tourism Research, Vol. 36 No. 3, available at: https://oi.org/10.1016/j. annals.2009.02.002

Williams, P., Soutar, G., Ashill, N. and Naumann, E. (2017), "Value drivers and adventure tourism: a comparative analysis of Japanese and Western consumers", Journal of Service Theory and Practice, Vol. 27 No. 1, pp. 102-122, available at: https://doi.org/10.1108/JSTP-05-2015-0116

Wong, K.H., Chang, H.H. and Yeh, C.H. (2019), "The effects of consumption values and relational benefits on smartphone Brand switching behavior", Information Technology and People, Vol. 32 No. 1, available at: https://doi.org/10.1108/ITP-02-2018-0064

World Health Organization (2015), "Food safety: what you should know?", available at: www.searo. who.int/entity/world_health_day/2015/whd-what-you-should-know/en/

Worsley, A., ; Wang, W.C. and Hunter, W. (2013), "Gender differences in the influence of food safety and health concerns on dietary and physical activity habits", Food Policy, Vol. 41, pp. 184-192.

Xiao, S. and Dong, M. (2015), "Hidden semi-Markov model-based reputation management system for online to offline (O2O) e-commerce markets", Decision Support Systems, Vol. 77, pp. 87-99. https://doi.org/10.1016/j.dss.2015.05.013.

Yang, W. and Mattila, A.S. (2016), "Why do we buy luxury experiences? ", International Journal of Contemporary Hospitality Management, Vol. 28 No. 9, available at: https://doi.org/10.1108/ijchm-11-20140579

Yani-de-Soriano, M., Hanel, P.H.P., Vazquez-Carrasco, R., Cambra-Fierro, J., Wilson, A. and Centeno, E. (2019), "Investigating the role of customers' perceptions of employee effort and justice in service recovery: a cross-cultural perspective", European Journal of Marketing, Vol. 53 No. 4, pp. 708-732, available at: https://doi.org/10.1108/EJM-09-2017-0570.

Ye, B.H., Barreda, A.A., Okumus, F. and Nusair, K. (2017), "Website interactivity and Brand development of online travel agencies in China: the moderating role of age", Journal of Business Research, Vol. 99, doi: 10.1016/j.jbusres.2017.09.046.

Yeo, V.C.S., Goh, S.K. and Rezaei, S. (2017), "Consumer experiences, attitude and behavioral intention toward online food delivery (OFD) services", Journal of Retailing and Consumer Services, Vol. 35, available at: https://doi.org/10.1016/j.jretconser.2016.12.013

Zolkepli, I.A. (2016), "Domination of mobile apps market: the effect of apps value on apps rating and apps costs in determining adoption", Proceedings of Penang International Symposium on Advanced in Social Sciences and Humanities, Royale Bintang, Penang.

\section{Corresponding author}

Amandeep Dhir can be contacted at: amannewgen@gmail.com
Proposition of food delivery apps 